\title{
LÓGICA FUZZY E TÉCNICA SAM PARA MODELAGEM PREVISIONAL DO OURO NO SETOR OESTE DA PROVÍNCIA MINERAL DO TAPAJÓS USANDO DADOS AEROGEOFÍSICOS E DE SENSORIAMENTO REMOTO
}

\author{
Thais Andressa Carrino ${ }^{1}$, Adalene Moreira Silvaa ${ }^{1}$, Nilson Francisquini Botelho ${ }^{1}$ \\ e Alexandre Augusto Cardoso da Silva² \\ Recebido em 13 maio, 2010 / Aceito em 15 julho, 2011 \\ Received on May 13, 2010 / Accepted on July 15, 2011
}

\begin{abstract}
Tapajós Mineral Province (TMP), the largest Brazilian gold province, lies in the south-central part of the Amazonian Craton. TMP is characterized by paleoproterozoic lithostratigraphic units that host gold mineralization of the same age. Based on this mineral potential, this paper used the processing and spatial modeling of regional airborne geophysical data (survey Block I - Tapajós Gold Province) and of remote sensing data (SAR-R99B and TM/Landsat 5) available to produce maps on gold favorability in the west portion of the TMP. Therefore, images of the K/eTh ratio and F parameter were produced aiming to enhance $\mathrm{K}$ enrichment. Lineament buffer image, interpreted using magnetometric images, SAR-R99B data and TM sensor, was produced in order to interpret relevant structural components. Using these products and the regional geological map available at PROMIN-Tapajós project, the fuzzy logic technique and the Spectral Angle Mapper classification were used to produce predictive maps of gold potential. Gold occurrences currently mapped were used to validate the results followed by a discussion on the performance of the production of regional predictive maps in areas with poor geological knowledge.
\end{abstract}

Keywords: gold mineralizations, airborne geophysics, remote sensing, fuzzy logic, Spectral Angle Mapper, predictive maps.

RESUMO. A Província Mineral do Tapajós (PMT) compreende a maior província aurífera do Brasil e localiza-se na parte centro-sul do Cráton Amazônico. A PMT é caracterizada por unidades litoestratigráficas paleoproterozoicas que hospedam mineralizações auríferas de mesma idade. Com base neste potencial mineral, este artigo objetivou o processamento e a modelagem espacial de dados aerogeofísicos regionais (levantamento Bloco I - Província Aurífera do Tapajós) e de sensoriamento remoto (SAR-R99B e TM/Landsat 5) disponíveis para a geração de mapas de favorabilidade aurífera do setor oeste da PMT. Para tal, imagens da razão K/eTh e do parâmetro F foram produzidas no intuito de se realçar o enriquecimento de K. Imagem de buffers de lineamentos, interpretados através de imagens magnetométricas, SAR-R99B e do sensor TM, foi gerada para a interpretação de componentes estruturais relevantes. Empregando-se estes produtos, além do mapa geológico regional disponibilizado no projeto PROMIN-Tapajós, foi utilizada a técnica lógica fuzzy e o classificador Spectral Angle Mapper objetivando a produção de mapas previsionais de ouro. Ocorrências de ouro atualmente conhecidas foram usadas para a validação dos resultados e uma discussão sobre o desempenho da geração de mapas previsionais regionais em terrenos com baixo conhecimento geológico foi realizada.

Palavras-chave: mineralizações auríferas, aerogeofísica, sensoriamento remoto, lógica fuzzy, Spectral Angle Mapper, mapas previsionais.

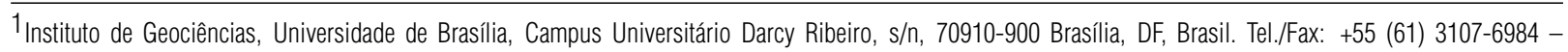
Emails: thais.carrino@gmail.com; adalene@unb.br; nilsonfb@unb.br

${ }^{2}$ Centro de Pesquisa e Desenvolvimento - CENPES - Petrobras, Av. Horácio de Macedo, 950, Cidade Universitária, Ilha do Fundão, 21941-915 Rio de Janeiro, RJ, Brasil. Tel.: +55 (21) 3865-7573 - Email: alexandreaugusto@petrobras.com.br
} 


\section{INTRODUÇÃo}

Mineralizações auríferas secundárias, ou do tipo placer, configuraram o principal bem mineral explotado na Província Mineral do Tapajós (PMT) desde 1958 até meados da década de 90, por meio da garimpagem rudimentar de aluviões, colúvios e elúvios (Peregovich et al., 2008). Esta região, localizada em partes dos estados do Amazonas e do Pará (Fig. 1), consiste em um terreno formado durante o paleoproterozoico (2,03-1,88 Ga), perfazendo mais de $90.000 \mathrm{~km}^{2}$ de área. Contrariamente ao grande potencial aurífero já discutido em vários trabalhos (Dardenne \& Schobbenhaus, 2001; Santos et al., 2001; Coutinho, 2008; entre outros), nenhuma mina de grande porte foi aberta nessa região, que ainda é intensamente carente de estudos geológicos mais detalhados e de investimentos governamentais e privados. De acordo com Rodrigues et al. (2008), 500 toneladas de ouro já foram extraídas da província, número este que pode ser maior em virtude da explotação não fiscalizada deste metal há mais de cinco décadas.

Os trabalhos sistemáticos iniciais na PMT consistiram em mapeamento geológico e levantamentos geoquímicos e geofísicos realizados nas décadas de 70 e 80 e que somente foram retomados com o PROMIN-Tapajós (Almeida et al., 2000; Bahia \& Quadros, 2000; Ferreira et al., 2000; Klein \& Vasquez, 2000; Vasquez \& Klein, 2000; Klein et al., 2001) e outros trabalhos (Santos et al., 2000, 2001, 2002, 2004; Juliani et al., 2002, 2005; Klein et al., 2002, 2004; Lamarão et al., 2005; Coutinho, 2008; Coutinho \& Fallick, 2008; Santos \& Coutinho, 2008).

Contribuições relevantes para a seleção de áreas favoráveis à prospecção de ouro já foram efetuadas por vários pesquisadores na PMT. Podem ser destacados os trabalhos do PROMINTapajós (Klein et al., 2001), de Silva (2003), Silva et al. (2007), Pedroso et al. (2001) e Jacques et al. (2008), que utilizaram diferentes metodologias para a produção de cartas metalogenéticas e mapas de previsão aurífera.

A carta metalogenética proposta por Klein et al. (2001) leva em conta todas as informações geológicas obtidas em campo, fotointerpretação e aerogeofísica regional, o que culminou na subdivisão da potencialidade aurífera em alta, moderada e baixa. Silva (2003) e Silva et al. (2007) selecionaram alvos potenciais de algumas regiões específicas da PMT por meio da interpretação visual de dados aeromagnetométricos e aerogamaespectrométricos regionais, assim como feito por Pedroso et al. (2001), que utilizaram também dados de radar de abertura sintética (Radarsat-1 e Jers-1). Jacques et al. (2008) propuseram um modelo prospectivo em toda a PMT, utilizando-se a técnica Razão por Semelhança (Likelihood Ratio), um método probabilístico, diri- gido pelos dados (ocorrências minerais). Neste estudo, foram utilizados os dados geoquímicos regionais, além do mapa geológico e os lineamentos apresentados em Klein et al. (2001).

Neste presente artigo, a técnica lógica fuzzy e o classificador supervisionado Spectral Angle Mapper foram selecionados para a previsão de potencialidade aurífera no setor oeste da PMT (Fig. 1), para o qual foram disponibilizados dados aerogeofísicos regionais e de sensoriamento remoto. Estas duas técnicas equivalem, respectivamente, ao método dependente do conhecimento e de pontos de treinamentos, no caso, ocorrências atualmente conhecidas de ouro nesta região da PMT.

\section{CONTEXTO GEOLÓGICO}

A PMT situa-se na porção centro-sul do Cráton Amazônico, um expressivo compartimento tectônico da Plataforma Sul-Americana que teve sua evolução tectônica há mais de 0,9 Ga (Almeida et al., 1981) e que foi compartimentado em províncias geocronológicas principalmente com base em dados isotópicos. Estas províncias são mais antigas a leste (>2,5Ga) e progressivamente mais jovens para sudoeste. Neste contexto, a Província TapajósParima (Santos et al., 2000, 2006), onde se situa a PMT, tem sua evolução relacionada à formação de um (Tassinari \& Macambira, 1999, 2004; Vasquez et al., 2002) ou mais arcos acrescidos a uma margem continental entre 2,03 e 1,88 Ga (Santos et al., 2001, 2004).

\section{Unidades litoestratigráficas da área de estudo}

As unidades paleoproterozoicas descritas abaixo, com exceção dos granitos Pepita, Caroçal e Igarapé Escondido, são portadoras de mineralizações de ouro na porção oeste da PMT, e estão apresentadas no mapa geológico da Figura 2, compilado dos mapas em escala 1:250.000 proveniente de Almeida et al. (2000) e Ferreira et al. (2000) no âmbito do projeto PROMIN-Tapajós.

0 Grupo Jacareacanga compreende uma associação de rochas metassedimentares e metavulcânicas de baixo grau metamórfico, como micaxisto, xisto máfico e quartzito (Ferreira et al., 2000). Segundo Santos et al. (2001), esta sequência metavulcanossedimentar foi submetida a uma deformação dúctil e a um metamorfismo em fácies xisto-verde que alcançou, localmente, fácies anfibolito. Datação de zircões detríticos pelo método U$\mathrm{Pb}$ forneceu idades entre $2098 \mathrm{Ma}$ e $2125 \mathrm{Ma}$ (Santos et al., 2000). Na área de estudo, esta unidade está localizada preferencialmente na parte sudoeste (Fig. 2).

0 Complexo Cuiú-Cuiú é composto por ortognaisse tonalítico e granodiorítico, por vezes migmatizado, com granito e dio- 

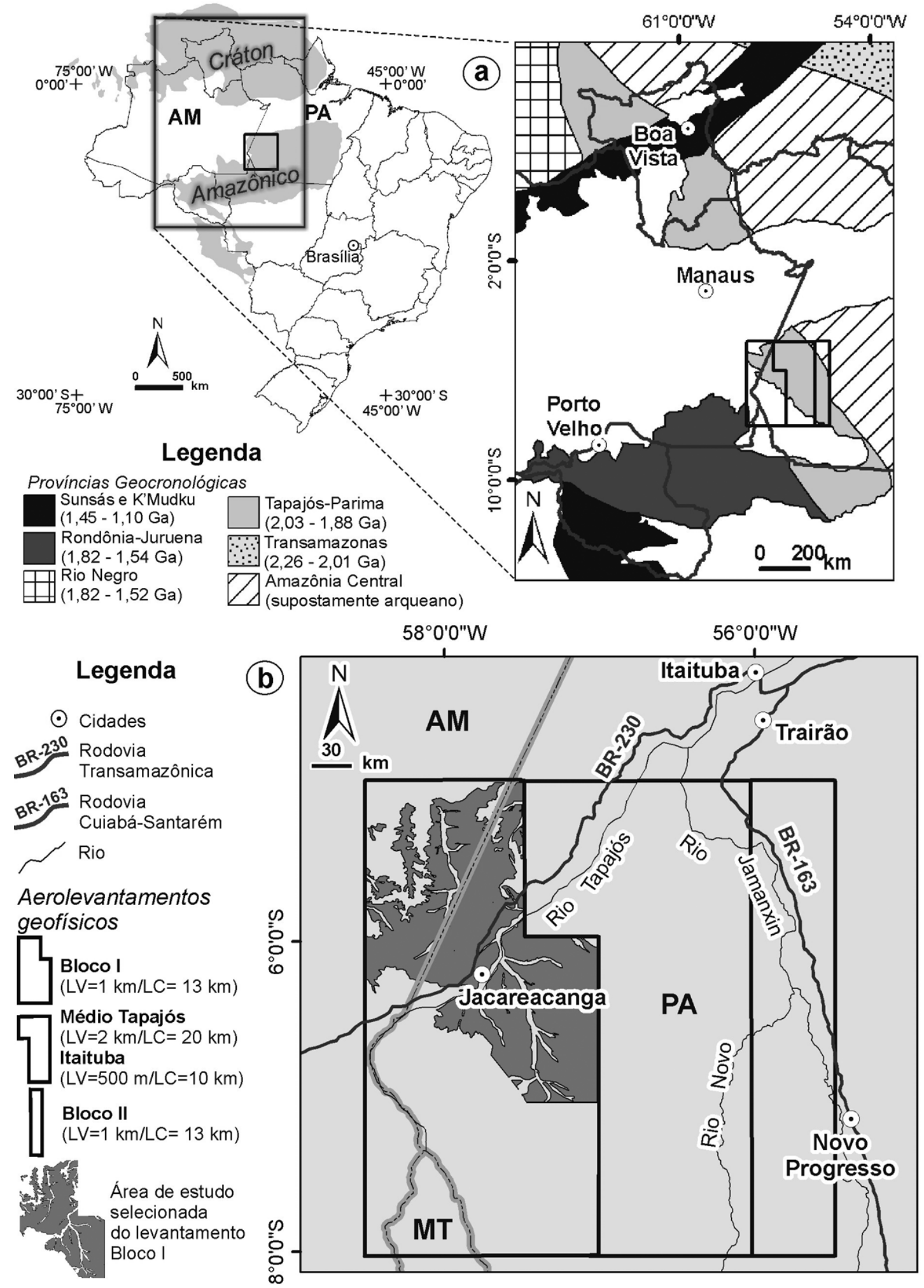

Figura 1 - Localização da Província Mineral do Tapajós (PMT) no Cráton Amazônico, especificamente na Província Geocronológica Tapajós-Parima (Santos et al., 2000, 2006) (a). Em (b), inserção da área de estudo no domínio do aerolevantamento geofísico Bloco I - Província Aurífera do Tapajós, além da indicação das principais vias de acesso e cidades. $\mathrm{LV}=$ linha de voo; $\mathrm{LC}=$ linha de controle. 


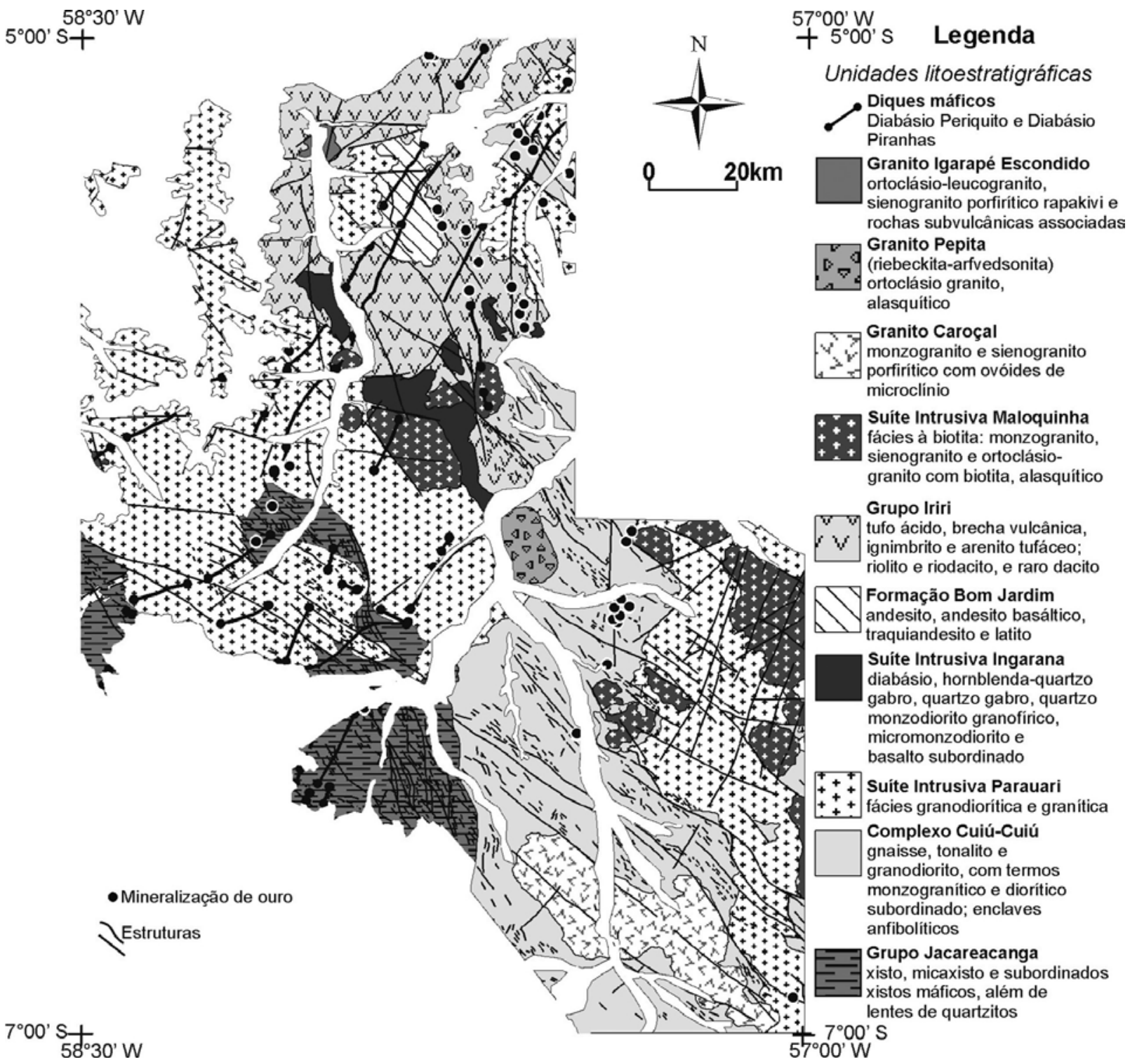

Figura 2 - Mapa geológico da área de estudo (modificado de Almeida et al., 2000; Ferreira et al., 2000).

rito associados com deformação dúctil e que hospedam enclaves de anfibolito, rochas metamáficas e paragnaisses. Granitos desta unidade forneceram idades U-Pb em zircão entre 2030 e $2005 \mathrm{Ma}$ (Santos et al., 2000, 2001). Esta unidade está presente nos setores norte e centro-leste da área de estudo (Fig. 2), sendo que na região dos prospectos Ouro Roxo e Cantagalo, granitos da Suíte Intrusiva Tropas (tonalito e granodiorito bandados de 1907-1892 Ma, com assinatura de arco de ilha) foram identificados por Santos et al. (2004). Entretanto, no mapa da Figura 2, estes corpos não foram individualizados, e foram mantidos como rochas do Complexo Cuiú-Cuiú.
A Suíte Intrusiva Parauari abrange rochas como granodiorito, monzogranito, raro tonalito e sienogranito (Klein et al., 2001). A datação de zircões de monzogranito pelo método de U-Pb forneceu idades entre 1881 e $1877 \mathrm{Ma}$ (Santos et al., 2004). Esta unidade é a mais extensa na área de estudo, abrangendo os setores norte, noroeste, centro-oeste e leste (Fig. 2).

A Suíte Intrusiva Ingarana é composta por rochas máficas como diabásio e gabro, com idades entre 1882 e $1878 \mathrm{Ma}$ (Santos et al., 2004). Na área de estudo, esta unidade encontra-se no setor central e apresenta-se alongada nas direções NW-SE e E-W. 
A Formação Bom Jardim é constituída por rochas vulcânicas de composição intermediária, abrangendo andesito, andesito basáltico, traquiandesito e latito (Almeida et al., 2000). 0 posicionamento estratigráfico desta formação ainda é incerto, podendo estar relacionado ao vulcanismo de $\sim 1,88 \mathrm{Ga}$ (Klein et al., 2001). Esta formação está inserida na parte norte da área de estudo (Fig. 2).

0 Grupo Iriri é subdividido na Formação Salustiano, composta por rochas vulcânicas ácidas (riolito, riodacito, dacito), e na Formação Aruri, que compreende rochas vulcanoclásticas (tufo, ignimbrito, brecha vulcânica) geralmente ácidas. Zircões de riodacito do Grupo Iriri foram datados por meio do método U-Pb, fornecendo idades entre 1878 e 1862 Ma (Santos et al., 2001). As rochas do Grupo Iriri estão localizadas no setor centro-norte da área de estudo (Fig. 2).

A Suíte Intrusiva Maloquinha abrange granitos por vezes controlados por falhas de direção NNW-SSE. A fácies à biotita ocorre na porção da PMT aqui estudada, compreendendo sienogranito, monzogranito e, raramente, feldspato alcalino granito com biotita (Klein et al., 2001). Datação U-Pb e Pb-Pb em zircões forneceu idades entre 1882 e $1864 \mathrm{Ma}$ (Santos et al., 2001; Lamarão et al., 2002). Esta suíte está inserida na parte leste e central do mapa da Figura 2.

0 Granito Caroçal compreende um batólito granítico alongado e condicionado por falhas NW-SE. É composto por monzogranito e sienogranito e apresenta uma afinidade cálcio-alcalina de alto $\mathrm{K}$, e caráter medianamente peraluminoso (Klein et al., 2001). A idade U-Pb entre 1874 e $1866 \mathrm{Ma}$ levou Santos et al. (2004) a incluir esta unidade na Suíte Intrusiva Maloquinha, assim como correlacionaram a unidade Granito Pepita a esta mesma suíte. Na área de estudo, esta unidade situa-se preferencialmente na parte sudeste (Fig. 2).

0 Granito Pepita consiste num batólito formado por (riebeckita-arfverdsonita) ortoclásio granito leucocrático. Estudos litogeoquímicos revelam um quimismo subalcalino a alcalino, levemente peraluminoso, similar aos granitos tipo-A. Granito desta unidade forneceu idade U-Pb em zircão entre 1876 e $1868 \mathrm{Ma}$ (Santos et al., 2004). Este granito está localizado no setor central da área de estudo (Fig. 2).

0 Granito Igarapé Escondido compreende um granito mesoproterozoico localizado pontualmente na porção norte da área de estudo (Fig. 2), no interflúvio do igarapé Escondido e do rio Parauari, consistindo num plúton granítico do tipo rapakivi em formato de stock que intrude a Formação Salustiano (Grupo Iriri) (Almeida et al., 2000).

Os diques máficos, denominados de Diabásio Periquito (Klein et al., 2001), intrudem as unidades paleoproterozoicas e fanerozoicas da PMT. Nesta unidade também estão inclusos os diques indiferenciados (Klein et al., 2001), sendo todo o conjunto caracterizado pela extensão quilométrica e orientação preferencial na direção NE-SW. As rochas compreendem diabásio e olivina diabásio, com idade de $507 \pm 4$ Ma obtida pelo método U-Pb em badeleíta (Santos et al., 2002). Santos et al. (2002) denominaram este enxame de dique de Diabásio Piranhas pela proximidade da amostra coletada em relação à ilha homônima inserida no rio Tapajós. Ainda de acordo com estes autores, os extensos diques do oeste da PMT não são mesozoicos e sim cambrianos e relacionados com o período de rifteamento que precedeu 0 início da sedimentação da Bacia Amazônica. Além disso, o sistema de rifteamento em 507 Ma pode ser contemporâneo com as atividades do final do Brasiliano ao longo das margens leste e sudeste do cráton.

\section{Contexto estrutural}

Santos \& Coutinho (2008) identificaram três domínios geológico-estruturais na PMT, designados por A (parte oeste), B (parte central) e C (parte leste) (Fig. 3a), e que foram afetados por três principais eventos deformacionais.

0 evento compressivo l é caracterizado por um pico de deformação em aproximadamente 1960 Ma e por um regime dúctil a dúctil-rúptil, afetando rochas do Grupo Jacareacanga, do Complexo Cuiú-Cuiú e granitos da Suíte Intrusiva Creporizão (esta última unidade sem ocorrência na área de estudo deste artigo). Deste evento, foram formados lineamentos de direção NW-SE (dextral) e N-S e NE-SW (sinistrais). 0 evento compressivo II possui a idade de $1880 \mathrm{Ma}$ e ocorreu em condições rúpteis. Os megalineamentos de direção NW-SE são derivados desta época e possuem bons registros na província, principalmente na região central (B) (Fig. 3a). Estes megalineamentos, denominados de Megassistema de Falhas Transcorrentes do Tapajós, compreendem falhas transcorrentes e subverticais com cinemática sinistral em geral. As falhas transcorrentes sinistrais afetam principalmente as rochas dos domínios oeste (A) e central (B), como rochas metassedimentares do Grupo Jacareacanga (ex., prospecto Espírito Santo), do Complexo Cuiú-Cuiú e das suítes intrusivas Creporizão, Parauari e Maloquinha. Falhas transcorrentes dextrais (ex., prospectos São José, Fazenda Pizon) e falhas extensionais também foram desenvolvidas neste período. 0 último evento deformacional é representado por um processo extensional, marcado por falhas relacionadas com o rifteamento da crosta que favoreceu a ascensão do magma tholeítico e formação de extensos diques máficos principalmente no setor oeste da PMT. 


\section{Mineralizações de ouro Aspectos gerais}

A formação da PMT como resultante de ambiente tectônico de margem continental ativa durante o Paleoproterozoico explica os principais modelos metalogenéticos das mineralizações auríferas atualmente propostos (Klein et al., 2001; Santos et al., 2001, Juliani et al., 2002, 2005, Coutinho, 2008).

Coutinho (2008) classificou os depósitos auríferos do Tapajós em mesozonais (tipo orogênico) e epizonais (correspondente ao tipo intrusion related), e determinaram duas épocas metalogenéticas em 1,95 Ga e 1,88 Ga a partir de idades-modelo em sulfetos.

Santos et al. (2001) propuseram quatro categorias de depósitos primários com base em observação mesoscópica dos corpos mineralizados, dados isotópicos e de microtermometria: (a) tipo orogênico hospedado em metaturbiditos; (b) tipo orogênico hospedado em rochas de arco magmático; (c) associado com intrusões (intrusion related), sendo depósitos de veios de quartzo epizonais; (d) associado com intrusões (intrusion related) do tipo stockwork epizonal. Os depósitos orogênicos estão associados com rochas hospedeiras do Complexo Cuiú-Cuiú e da Suíte Intrusiva Tropas e, em menor grau, com rochas metassedimentares do Grupo Jacareacanga. Já os depósitos do tipo intrusion related estão hospedados principalmente em rochas das suítes intrusivas Parauari e Maloquinha, seguidos de rochas vulcânicas do Grupo Iriri e em granitos pós-colisionais da Suíte Intrusiva Creporizão, sendo as principais alterações hidrotermais a sericitização e feldspatização e, por vezes, epidotização e carbonatação. De acordo com Santos et al. (2001), nenhuma mineralização de ouro foi verificada em unidades mais jovens que a Suíte Intrusiva Maloquinha. A partir da datação desta unidade, os autores obtiveram a idade máxima para os depósitos do tipo intrusion related em 1,86 Ga.

Depósito aurífero mesotermal/mesozonal estruturalmente controlado também foi identificado na porção sudeste da PMT por Klein et al. (2002). Klein et al. (2004), a partir de petrografia e dados de inclusões fluidas, caracterizaram um evento mineralizador concomitante à deformação transcorrente e à colocação dos granitos da Suíte Intrusiva Creporizão no prospecto Patinhas entre aproximadamente 1,97 e 1,95 Ga.

Mineralizações de ouro epitermal foram reconhecidas por Dreher et al. (1998) e Juliani et al. (2005, 2008). Um sistema epitermal do tipo adulária-sericita foi identificado por Dreher et al. (1998) na região dos prospectos Joel e Davi, que não se inserem na área de estudo do presente artigo. Nestes prospectos, o mineral adulária foi reconhecido, aparecendo em cavida- des fraturadas de rochas máficas hidrotermalmente afetadas, e associado com veios de quartzo mineralizados. A alteração hidrotermal, classificada como de natureza propilítica, caracterizase por minerais como clorita, calcita, sericita e epídoto. Juliani et al. $(2005,2008)$ verificaram mineralizações epitermais de alta sulfetação na região do rio Jamanxim, com alunita magmáticohidrotermal associada com brechas hidrotermais hospedadas em complexos vulcânicos riolíticos que, por sua vez, encontramse relacionados com rochas graníticas com idade variando entre 1,89 e 1,87 Ga. A alunita apresenta-se disseminada em halos de alteração argílica avançada que envelopam sílica vuggy. Amostras de alunita datadas pelo método Ar-Ar forneceram idades de 1869 a 1846 Ma para a mineralização de ouro.

\section{Setor oeste da PMT}

0 setor oeste da PMT é caracterizado por seis áreas potenciais mapeadas pelo PROMIN-Tapajós (Klein et al., 2001), conforme mostrado na carta metalogenética da Figura 3b.

A região onde se inserem os prospectos Ouro Roxo e Cantagalo (Fig. 3b) é caracterizada por alteração hidrotermal como a sericitização/fengitização, epidotização, carbonatação, silicificação e sulfetação (predomínio de pirita). 0 controle estrutural é marcado pela zona de cisalhamento principal de direção N-S, além de zonas menos extensas, de 2 a $3 \mathrm{~km}$, e com orientação NNE-SSW, conforme observado no prospecto Ouro Roxo (Santos et al., 2001; Veloso et al., 2008). As rochas hospedeiras consistem em ortognaisses do Complexo Cuiú-Cuiú (Klein et al., 2001) ou granitos da Suíte Intrusiva Tropas (Santos et al., 2001), e tais mineralizações foram inclusas na categoria de ouro orogênico hospedado em arco magmático por Santos et al. (2001). Destaca-se que, nesta região, ocorrências de ouro hospedadas em rochas da Suíte Intrusiva Tropas possuem semelhanças com as ocorrências hospedadas em rochas do Complexo CuiúCuiú (depósitos do tipo orogênico/mesozonal) apesar de serem mais jovens ( 1,9 Ga) (Santos et al., 2001).

A região onde se localiza o prospecto Chico Torres (Fig. 3b) é marcada por prospectos com dependência estrutural NW-SE, conforme verificado em garimpo homônimo (Santos \& Coutinho, 2008), e que reflete a instalação de zona de cisalhamento com mesma orientação. Destaque é dado à presença de alterações hidrotermais como a sericítica, além de epidotização, silicificação e sulfetação (Klein et al., 2001; Coutinho \& Fallick, 2008).

0 setor que abrange os prospectos Seta de Ouro e 12 de Outubro (Fig. 3b) é caracterizado por rochas hospedeiras vulcânicas ácidas a intermediárias (Grupo Iriri e Formação Bom Jardim), e alterações hidrotermais das quais se destacam a silicificação e 


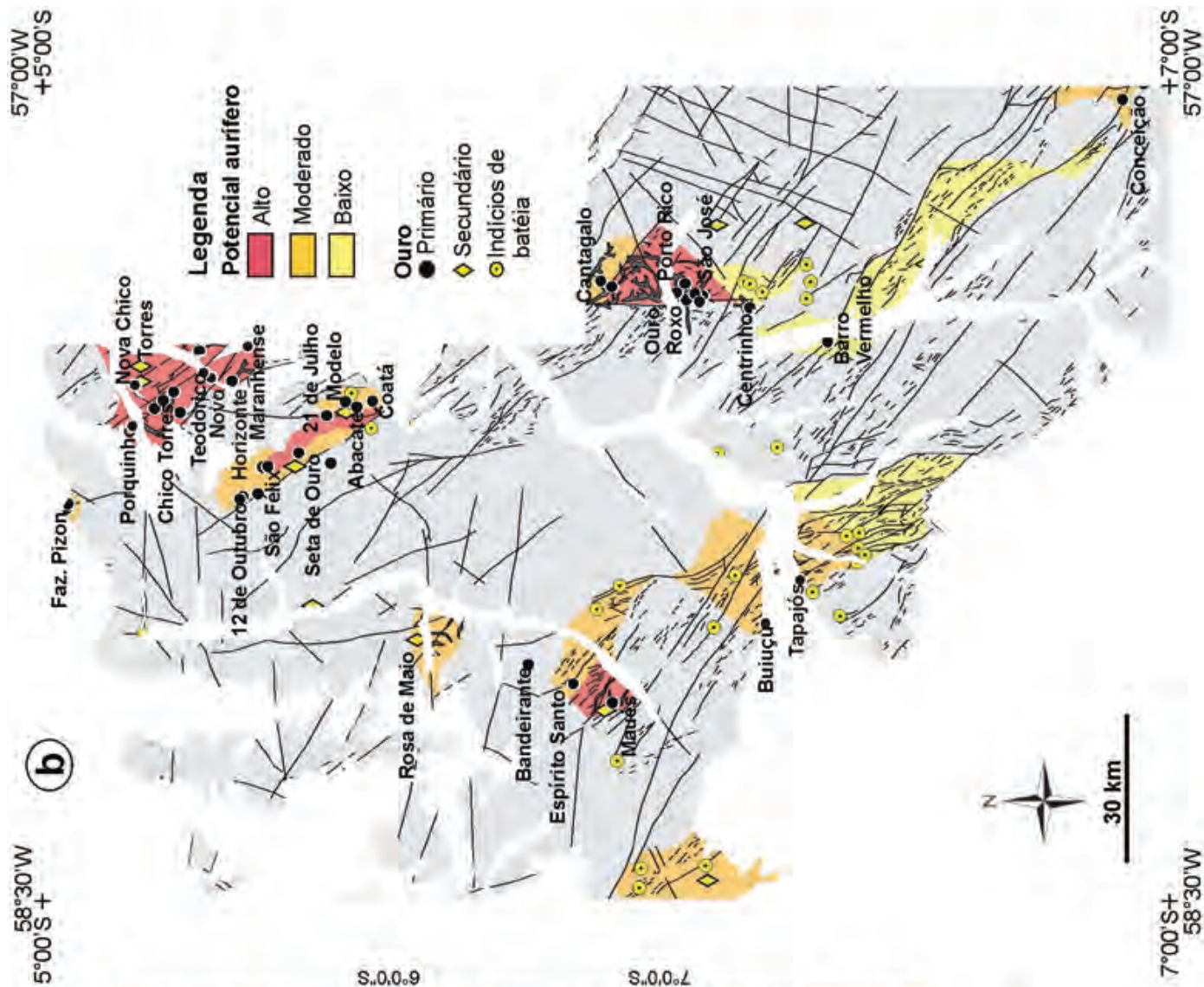

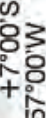

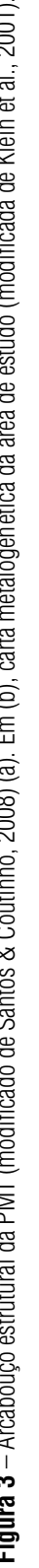
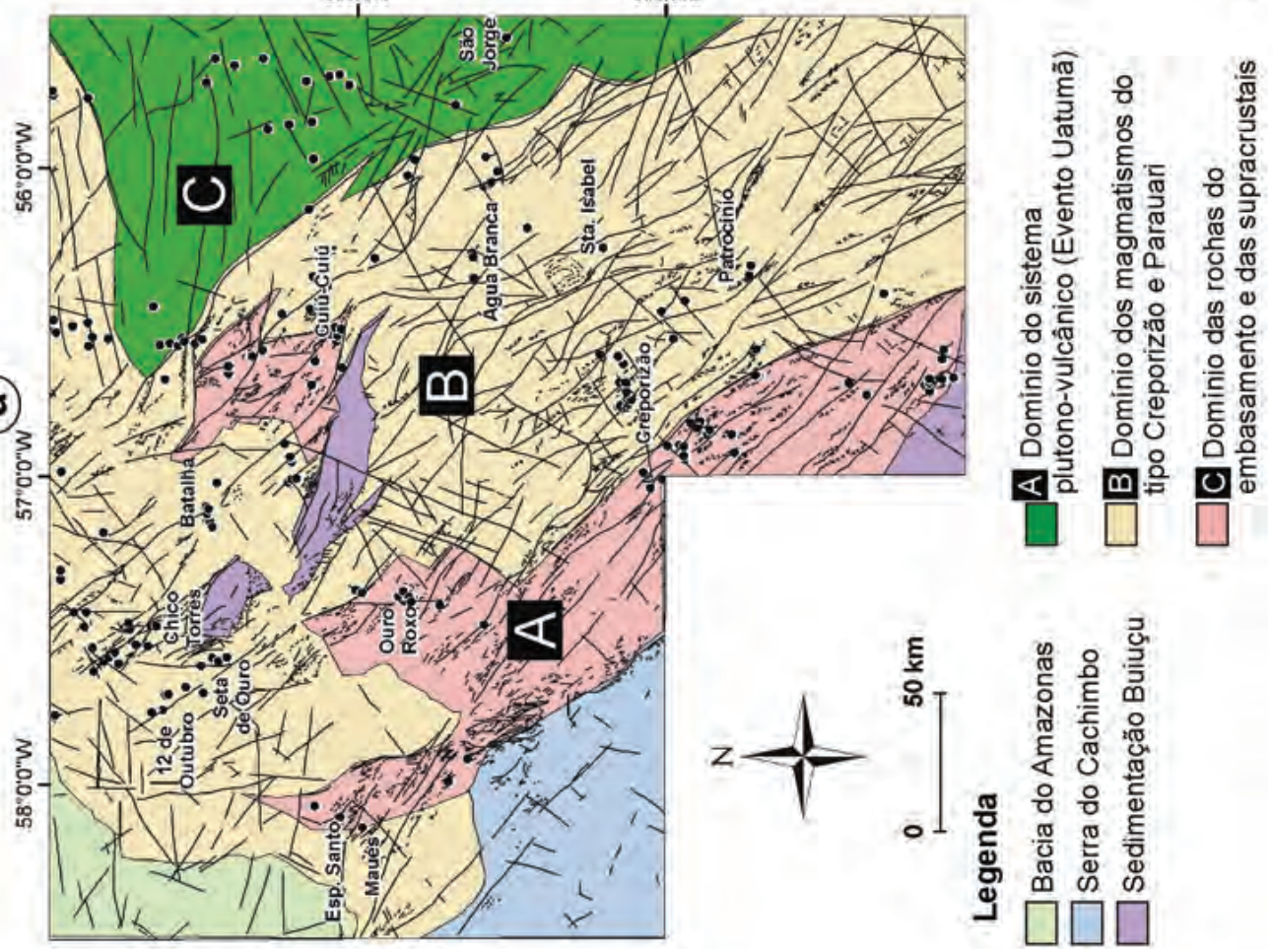
sulfetação (Klein et al., 2001; Pereira et al., 2008). Em suma, as mineralizações associam-se com stockworks e veios de quartzo, e com controles estruturais de direção NE-SW e NW-SE (Klein et al., 2001).

Os prospectos Maués e Espírito Santo (Fig. 3b) foram inseridos por Santos et al. (2001) na categoria de depósitos de ouro hospedados em metaturbiditos caracterizados por fácies xistoverde. A mineralização associa-se com veios de quartzo sulfetados (predomínio de pirita), por vezes boudinados, encaixados em xistos do Grupo Jacareacanga (Klein et al., 2001). Estes veios mineralizados estão relacionados com sericita e clorita e com zonas de cisalhamento de direção NW-SE (Santos et al., 2001; Santos \& Coutinho, 2008). Segundo Pinto et al. (2009), há forte tendência de que o ouro seja do tipo lode.

A região do prospecto Rosa de Maio (Fig. 3b) caracteriza-se por alteração hidrotermal como a sericitização, metassomatismo potássico, além da silicificação (Botelho et al., 2009; Pinto et al., 2009). Estruturas concêntricas podem estar relacionadas com cúpulas dos granitos mineralizados da Suíte Intrusiva Parauari. 0 prospecto Bandeirante é caracterizado por granitos da Suíte Intrusiva Parauari feldspatizados e por marcante intemperismo, fato este que fortalece a questão de enriquecimento supergênico na região (Pinto et al., 2009; Almeida et al., 2000).

A região do prospecto Conceição (Fig. 3b) é marcada por ocorrências de brecha hidrotermal e veios de quartzo sulfetados associados com granitos da Suíte Intrusiva Parauari. Há uma dependência estrutural das mineralizações por falhas NW-SE (Klein et al., 2001). As mineralizações deste prospecto foram incluídas por Santos et al. (2001) na categoria de ouro do tipo lode, associadas com estruturas regionais de direção NNW-SSE.

\section{MATERIAIS E MÉTODOS}

\section{Dados geológicos}

Mapas geológicos do PROMIN-Tapajós (Almeida et al., 2000; Ferreira et al., 2000), em escala 1:250.000, foram georreferenciados em ambiente SIG para criação de layers referentes às ocorrências auríferas, estruturas e unidades litoestratigráficas, utilizando-se a projeção Universal Transversa de Mercator, datum horizontal SAD-69, zona 21 sul.

\section{Imagens de sensoriamento remoto e processamento}

Foram selecionadas 8 faixas de voo de radar de abertura sintética (synthetic aperture radar - SAR) da Missão Terra do Meio Oeste, adquiridas pela plataforma aérea R99B em abril de 2006, a uma altitude de aproximadamente $10668 \mathrm{~m}$. Estas imagens são carac- terizadas pelo emprego da banda $L$, polarização $\mathrm{HH}$, resolução espacial em alcance e azimute de $18 \mathrm{~m}$, tamanho de pixe/ de $15 \mathrm{~m}, 8$ multivisadas, sentido do imageamento para oeste, e ângulo de incidência (de near ao far range) variando de $45^{\circ}$ a $81,10^{\circ}$. Estes dados foram cedidos pelo Centro Técnico Operacional do Sistema de Proteção da Amazônia (CENSIPAM) de Belém em formato 8 bits.

A radiometria das imagens SAR-R99B foi homogeneizada por meio da correção do padrão de antena, que foi realizada a cada faixa imageada, às quais uma função de ordem 5 foi selecionada. Devido ao imageamento multivisada (8 looks), uma menor resolução espacial (no caso, de $18 \times 18 \mathrm{~m}$ em alcance e azimute) foi determinada para a Missão Terra do Meio Oeste. Por outro lado, esta diminuição da resolução espacial por meio das múltiplas visadas reduz os ruídos inerentes às imagens de SAR, o speckle. Com a análise visual dos segmentos, não se verificou o ruído e, por isso, não foi necessária a aplicação de filtros adaptativos para a suavização dos mesmos.

0 passo final compreendeu a correção geométrica das imagens, utilizando-se 82 pontos de controle a partir de cartas topográficas em escala 1:250.000. 0 erro médio quadrático resultante compreendeu $17,58 \mathrm{~m}$.

Uma imagem do sensor Thematic Mapper (TM/Landsat 5), órbita/ponto 229/65 de 23 de junho de 1997, foi empregada para cobrir a área de estudo na qual houve ausência de um segmento de radar não imageado. Esta cena multiespectral é caracterizada por resolução espacial aproximada de $30 \mathrm{~m}$ e foi retificada através do uso de 54 pontos de controle com base nas cartas topográficas 1:250.000, gerando-se um erro quadrático médio de 11,052 m.

\section{Aerogeofísica e processamento}

Os dados do aerolevantamento Bloco I - Província Aurífera do Tapajós foram obtidos pela empresa Lasa Engenharia e Prospecção S.A. entre junho e novembro de 1997. Consistem em dados magnetométricos e gamaespectrométricos caracterizados por espaçamento das linhas de voo (N-S) e de controle (E-W) de 1 e $13 \mathrm{~km}$, respectivamente, e coletados em altura de voo de 100 metros. 0 sistema aeromagnético Picodas, modelo PDAS 1000 (aquisiçã̃o e compensação), foi acoplado a um sensor de vapor de césio modelo CS-12 da SCINTREX, com resolução de 0,001 nT, e montado na cauda da aeronave. Para o registro da radiação gama referente aos canais de $\mathrm{K}, \mathrm{eU}$, eTh e da contagem total, foi selecionado 0 sistema Picodas, modelo PGAM, de 256 canais espectrais. 0 volume total de cristais de iodeto de sódio (Nal) ativado a tálio consistiu em 2048 polegadas cúbicas para dois conjuntos de cristais voltados para baixo e 512 polegadas cúbicas para 
dois conjuntos de cristais voltados para cima (Lasa Engenharia e Prospecções S.A., 1998).

0 banco de dados geofísico utilizado foi pré-processado por Silva (2003), que empregou o micronivelamento de Minty (1991) a partir do algoritmo criado por Blum (1999), e aplicou o interpolador curvatura mínima para geração das seguintes imagens caracterizadas por tamanho de célula de $250 \mathrm{~m}$ : K, eTh, eU, contagem total, razão K/eTh, e a do campo magnético anômalo. A partir do banco de dados de Silva (2003), optou-se pela produção da imagem do parâmetro

$$
F=\left(K * \frac{e U}{e T h}\right)
$$

(Efimov, 1978), que compreende uma tentativa de distinção de enriquecimento de $\mathrm{K}$ em relação à informação de background geológico, ou seja, as variações litológicas do meio. Este parâmetro reflete a abundância de $\mathrm{K}$ associada à razão U/eTh, com a abundância de eU relacionada à razão K/eTh.

As transformações lineares do campo magnético anômalo aqui utilizadas foram geradas por Silva (2003). Estas transformações geralmente não definem diretamente a distribuição das fontes magnéticas causativas, mas facilitam a construção de um entendimento geral da natureza das mesmas e as interpretações geológicas (Blakely, 1996). Compreendem as derivadas horizontais (Dx e Dy) e a derivada vertical (Dz) de primeira ordem do campo magnético anômalo. A partir destas derivadas, Silva (2003) gerou a imagem da amplitude do sinal analítico (ASA), cujos picos são simétricos e ocorrem diretamente sobre as bordas de grandes corpos e no centro de corpos estreitos. Este filtro permite uma rápida identificação da posição das fontes e da geometria magnética (Nabighian, 1972, 1974; Roest et al., 1992).

\section{Métodos de análise prospectiva}

A proposta aqui apresentada para a região oeste da PMT compreende a aplicação de análise espacial por meio da lógica fuzzy e o uso do algoritmo hiperespectral Spectral Angle Mapper (SAM) a fim de apresentar um primeiro input a respeito da favorabilidade mineral desta região, na qual se inserem importantes prospectos como o Maués, 12 de Outubro, Rosa de Maio, Seta de Ouro, Chico Torres, Porquinho, Ouro Roxo, São José entre outros. A área modelada foi restrita aos dados do aerolevantamento Bloco I - Província Aurífera do Tapajós, com a subtração das coberturas sedimentares proterozoicas (Formação Buiuçu), paleozoicas (Bacia do Alto Tapajós), mesozoicas (Bacia do Amazonas) e coberturas superficiais (Fig. 1b). Anterior à especificação dos thresholds (limiares) das duas técnicas adotadas para este estudo de caso, uma explicação teórica das mesmas é apresentada abaixo.

\section{Lógica fuzzy e Spectral Angle Mapper}

A lógica fuzzy baseia-se na simplificação de dados rasterizados por meio da fuzificação, ou seja, seleção de funções de pertinência fuzzy que permitem o escalonamento dos dados originais em graus de variabilidade entre 0 (pertinência ausente) e 1 (pertinência total). A aplicação subjetiva de uma função de pertinência fuzzy (small, large, categórico, entre outros) permite a modificação do mapa em dados ordenados ou intervalares, gerando as possibilidades fuzzy (An et al., 1991; Bonham-Carter, 1994). Para o caso das pertinências large e small, a forma da função é determinada pelo expert por meio dos parâmetros ponto médio, que significa o valor de 0,5 de pertinência fuzzy, e espaIhamento, que indica o quão rápido a pertinência fuzzy decresce do valor 1 ao 0 .

Os operadores fuzzy mais comuns compreendem E, OU, produto algébrico, soma algébrica e fuzzy gama, e podem ser revistos de forma aprofundada em An et al. (1991) e Bonham-Carter (1994).

0 operador fuzzy gama é interessante pelo fato de contrabalancear os efeitos minimizantes do produto algébrico fuzzy com os valores maximizantes do operador soma algébrica fuzzy, caracterizando-se pela minimização de influência tendenciosa para a seleção de alvos (Bonham-Carter, 1994) (Eq. 1):

$$
\mu_{\text {gamma }}=\left(\mu_{\text {soma }}\right)^{\gamma} *\left(\mu_{\text {produto }}\right)^{1-\gamma},
$$

onde $\mu_{\text {gama }}$ é a possibilidade fuzzy resultante, e $\gamma$ é o parâmetro escolhido na variação entre 0 e 1. Quando $\gamma$ é 1, a combinação fuzzy gama compreende 0 resultado da soma algébrica fuzzy. Quando $\gamma$ é 0 , o resultado final consiste somente na contribuição do produto algébrico fuzzy (An et al., 1991; Bonham-Carter, 1994). Em geral, valores mais usuais de $\gamma$ na literatura variam de 0,7 a 0,9 .

0 algoritmo Spectral Angle Mapper (SAM) foi criado originalmente para aplicação em dados de sensoriamento remoto óptico de alta resolução espectral (Kruse, 1998; Rowan \& Mars, 2003). Todavia, esta classificação supervisionada também foi estendida à utilização em dados de outras naturezas, como os geofísicos, a exemplos de estudos de caso desenvolvidos por Miethke et al. (2007) e Carrino et al. (2008).

De acordo Kruse et al. (1993) e Kruse (1998), o SAM baseiase nas seguintes premissas: os pixe/s das imagens selecionadas à classificação são vetorizados e, para cada pixe/, são extraídos os valores correspondentes das $n$ imagens e armazenados 


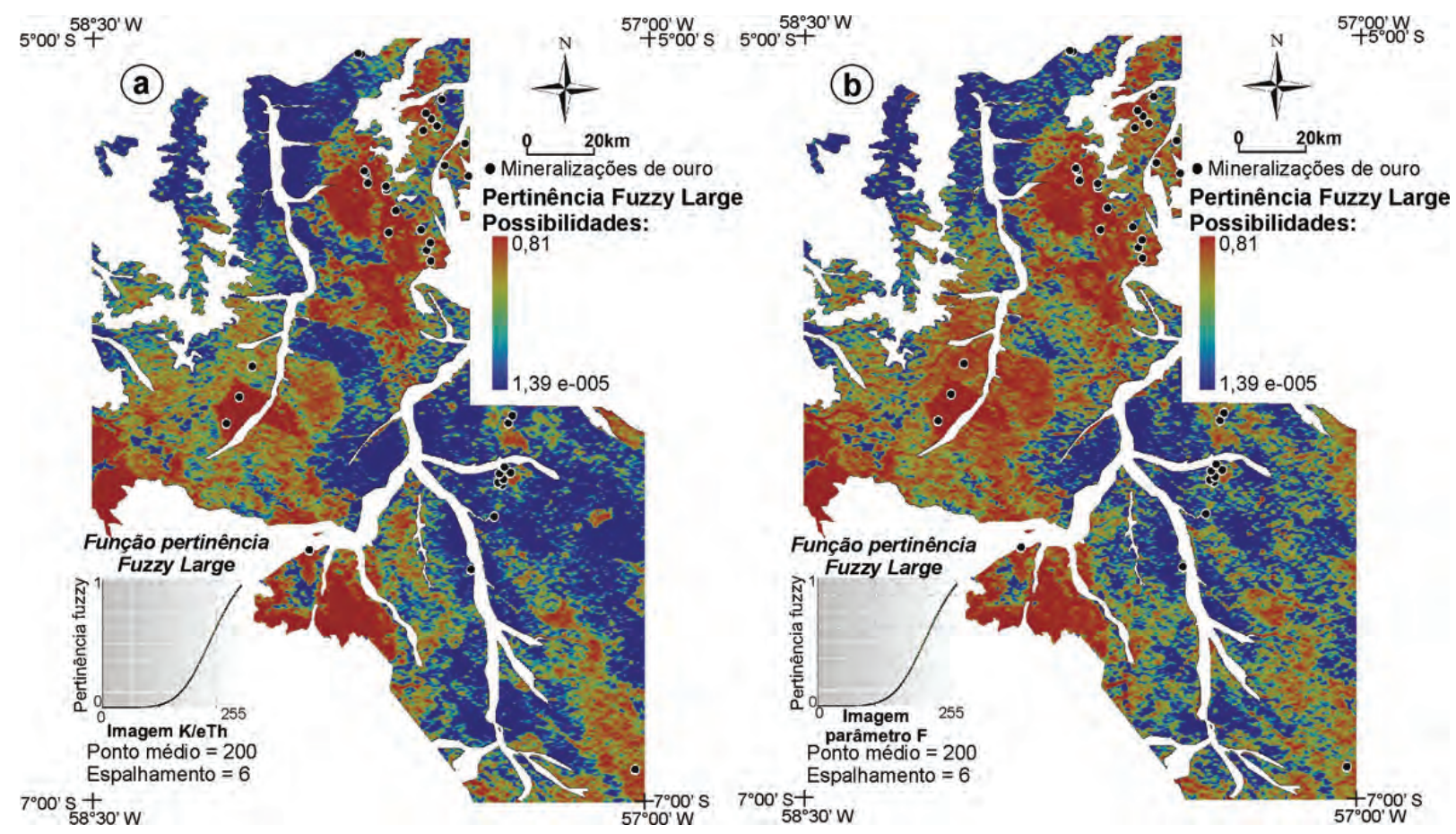

Figura 4 - Imagens da razão K/eTh (a) e do parâmetro F (b) fuzificadas a partir da seleção da pertinência fuzzy large.

em vetores-teste $t$, de tamanho $1 \times n$. Similarmente, os endmembers ou pontos de treinamento (ocorrências de ouro, pontos geoquímicos anômalos, entre outros) também são tratados como vetores $r$ de tamanho $1 \times n$. 0 princípio desta técnica compreende a comparação de ambos os conjuntos de vetores (imagens e endmembers) por meio do ângulo de similaridade (em radianos) que é determinado subjetivamente. Este ângulo compreende 0 arco-cosseno $(\alpha)$ do produto escalar entre os vetores $t$ e $r$, normalizado pelo produto de seus respectivos módulos. 0 resultado final esperado consiste nos menores valores do ângulo, pois implicam em maior semelhança da comparação dos vetores $t \mathrm{e}$ $r$. Este resultado pode ser expresso por meio de imagens rules (em níveis de cinza), ou por meio de imagens classificadas pela determinação de uma cor específica a cada endmember .

\section{Mapas prospectivos gerados}

Os dados de entrada para a produção dos mapas previsionais equivaleram às unidades litoestratigráficas segundo Almeida et al. (2000) e Ferreira et al. (2000), imagens aerogeofísicas e lineamentos interpretados com base em imagens magnetométricas e de sensoriamento remoto. As justificativas para a utilização de tal acervo são esclarecidas da seguinte maneira:

- mapa geológico (Almeida et al., 2000; Ferreira et al., 2000): o conhecimento geológico compreende uma im- portante evidência para a exploração aurífera desta região, destacando-se rochas hospedeiras como as do Complexo Cuiú-Cuiú, Suíte Intrusiva Parauari e Grupo Iriri como aquelas com maior quantidade de ocorrências auríferas já mapeadas (vide Fig. 2);

- imagens aerogeofísicas: as imagens da razão K/eTh e do parâmetro $\mathrm{F}$ permitem 0 reconhecimento de enriquecimento de K (Biondi et al., 2001; Quadros et al., 2003; Soares et al., 2004), e este radioelemento pode associar-se com alteração hidrotermal, conforme observado em muitos dos prospectos abordados, caracterizados por alterações como sericitização e feldspatização. A partir das imagens individuais de K/eTh e parâmetro $\mathrm{F}$ (Fig. 4), além da imagem ternária de K/eTh, parâmetro F e K no sistema de cores RGB (Fig. 5), é possível verificar que as ocorrências de ouro já cartografadas encontram-se relacionadas com um domínio litogeofísico marcado por com altos valores de $\mathrm{K}$, K/eTh e parâmetro $\mathrm{F}$, refletindo um ambiente geológico de rochas hospedeiras vulcânicas ácidas, granitos e rochas metassedimentares;

- lineamentos: foram interpretados na escala 1:250.000 principalmente por meio das imagens SAR-R99B e TM/Landsat 5, além do uso conjunto de imagens magnetométricas (derivadas em $x$, y e $z$ de primeira ordem do 


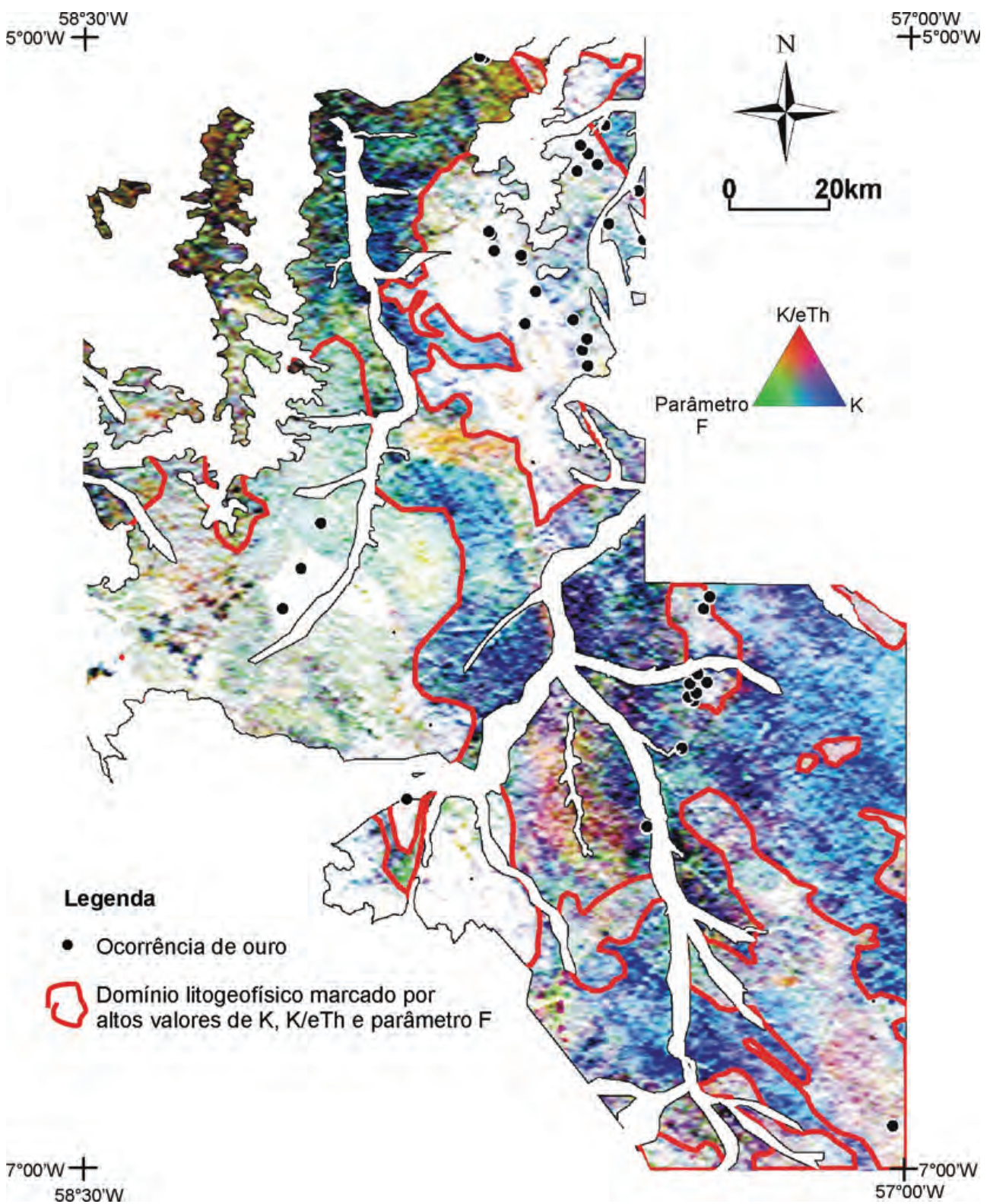

Figura 5 - Mapa das principais zonas de influência metalogenética indicadas a partir de buffers de lineamentos, associado com rosetas azimutais dos principais trends auríferos.

campo magnético anômalo e ASA). Buffers foram gerados e analisados de acordo com os três trends auríferos propostos por Metelo et al. (2008) que ocorrem na área de estudo: São Jorge-Chico Torres, Patrocínio-Espírito Santo e Santa Isabel-Ouro Roxo (Fig. 6).

Na etapa da aplicação da lógica fuzzy, os dados foram fuzificados da seguinte maneira (Fig. 7):

(a) aplicação da função de pertinência fuzzy categórico ao mapa geológico, a partir de critério subjetivo, porém atre- lado ao conhecimento atual da relação de mineralizações em determinadas rochas hospedeiras, a exemplo das informações fornecidas no PROMIN-Tapajós (Klein et al., 2001). Desta maneira, foram atribuídas as seguintes possibilidades fuzzy: 0,95 para rochas o Complexo CuiúCuiú, 0,90 para hospedeiras da Suíte Intrusiva Parauari, 0,70 para rochas vulcânicas do Grupo Iriri, 0,65 para rochas vulcânicas intermediárias da Formação Bom Jardim, 0,60 para rochas metassedimentares do Grupo Jacareacanga, 0,50 para granitos da Suíte Intrusiva Maloquinha, 


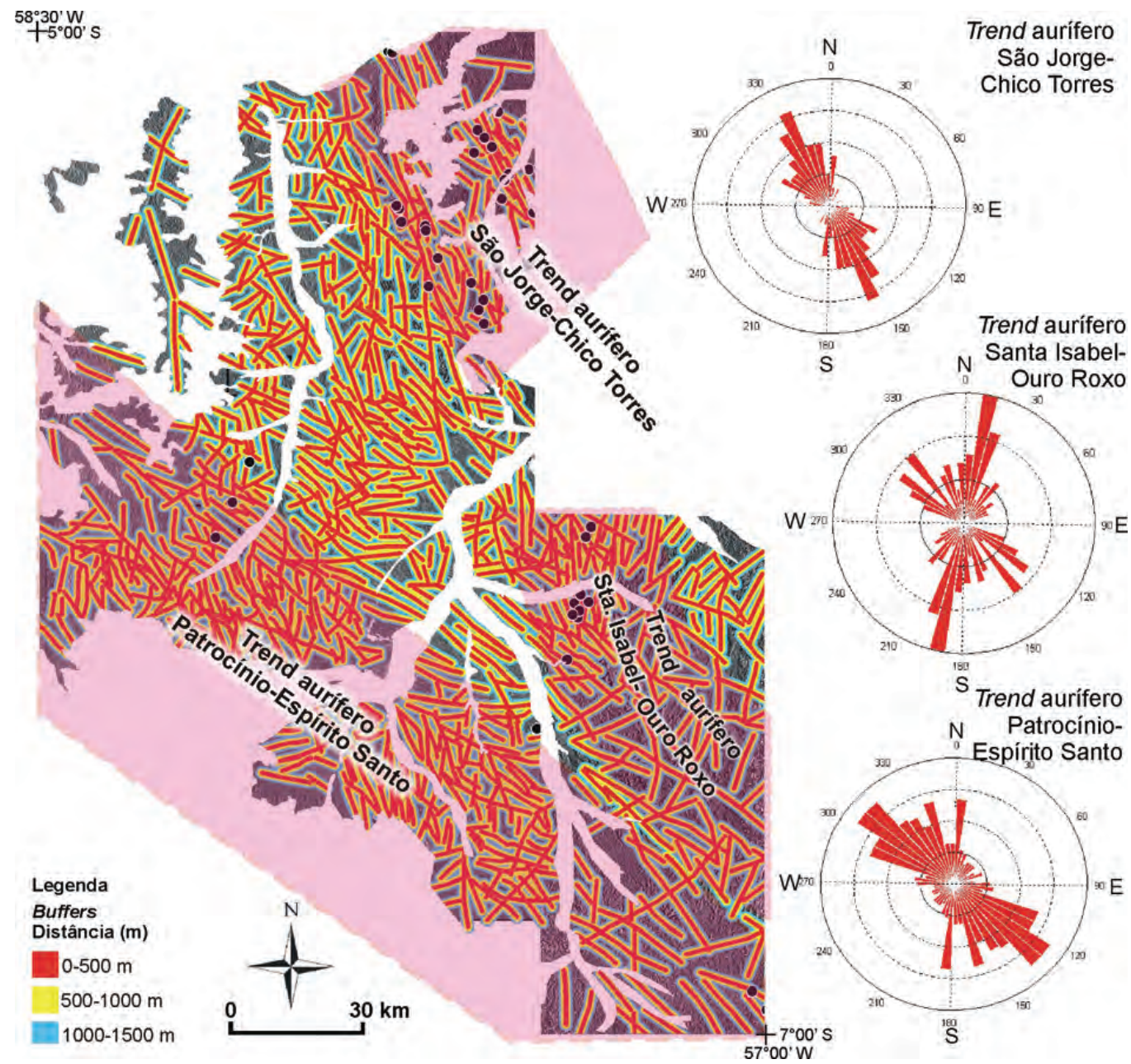

Figura 6 - Composiç̧ão ternária RGB das imagens da razão K/eTh, do parâmetro F e do canal do K.

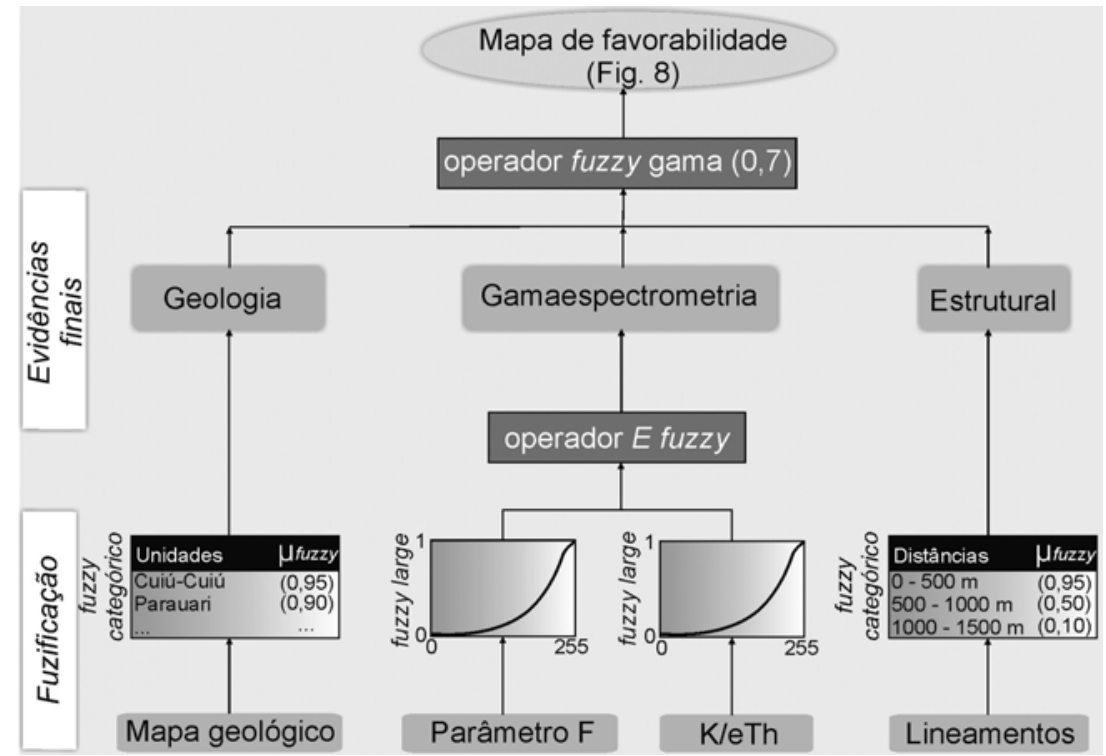

Figura 7 - Síntese das etapas envolvidas na aplicação da lógica fuzzy. 
0,40 para rochas máficas da Suíte Intrusiva Ingarana (onde veios de quartzo auríferos já foram constatados); 0,05 para os granitos Pepita, Caroçal e Igarapé Escondido. Esta evidência fuzificada foi designada como 'Geologia';

(b) uso da função de pertinência fuzzy categórico para determinação de possibilidades fuzzy nos dados de buffers de lineamentos. Para o intervalo de 0-500 m de distância, selecionou-se uma pertinência de 0,95; entre 500-1000 m, determinou-se a pertinência de 0,50; para 0 intervalo das distâncias entre 1000-1500 m, uma pertinência baixa de 0,05 foi selecionada. Esta evidência resultante foi denominada de 'Lineamentos';

(c) utilização da função de pertinência fuzzy large para as imagens do parâmetro $\mathrm{F}$ e da razão K/eTh, conforme mostrado na Figura 4. Esta função atribui altas possibilidades fuzzy aos dados originais caracterizados por maiores valores numéricos.

A combinação dos dados fuzificados foi realizada nas seguintes etapas (Fig. 7):

(a) operador E fuzzy aplicado às imagens fuzificadas do parâmetro $\mathrm{F}$ e da razão K/eTh, produzindo-se a evidência aqui denominada de 'Gamaespectrometria';

(b) reunião das evidências Geologia, Gamaespectrometria e Lineamentos por meio do operador fuzzy gama 0,7, produzindo-se 0 mapa final apresentado na Figura 8.0 pósprocessamento da lógica fuzzy compreendeu a quantificação das áreas classificadas, por intervalos de pertinência fuzzy, conforme apresentado na Tabela 1.

Os mesmos dados utilizados para o processamento via lógica fuzzy foram empregados para 0 uso do classificador SAM. Seguindo os preceitos de tal método, os passos aplicados estão resumidos na Figura 9 e consistiram em:

(a) as imagens fuzificadas do mapa geológico e dos lineamentos, além das imagens do parâmetro $\mathrm{F}$ e da razão $\mathrm{K} / \mathrm{eTh}$, foram redimensionadas para 0 formato digital de 8 bits, a fim de manter a integridade de todos, visto que os dados originais são caracterizados por distintas escalas de medidas (dados contínuos);

(b) extração das assinaturas pontuais das ocorrências de ouro constatadas pela CPRM, também denominadas de endmembers, a partir dos pixe/s correspondentes (tamanho $=250 \mathrm{~m}$ ) nas quatro imagens reescalonadas para 256 níveis de cinza. Conjuntos de endmembers foram obtidos por meio da individualização de seis regiões auríferas marcadas pelos seguintes prospectos: Ouro Roxo e Cantagalo, Conceição, Maués e Espírito Santo, Bandeirante e Rosa de Maio, Seta de Ouro e 12 de Outubro, e Chico Torres;

(c) aplicação do algoritmo SAM, a partir da determinação subjetiva de ângulos de similaridade ( $\alpha$ ) a cada uma das seis regiões auríferas. Desta forma, foram geradas seis classes identificadas por seis cores diferentes, conforme mostrado no mapa prospectivo da Figura 10. A Tabela 2 mostra o pós-processamento do resultado gerado pelo uso da técnica SAM, a partir da quantificação da área total classificada, procedimento este aplicado a cada uma das seis áreas cujos conjuntos individuais de endmembers foram extraídos.

\section{RESULTADOS E DISCUSSÕES}

A interpretação de lineamentos da porção oeste da província (Fig. 6) mostra a diversidade de trends estruturais na região e como as diferentes direções estão relacionadas a cada uma das seis principais áreas auríferas. Desta maneira, para a geração de mapas previsionais aqui proposta, somente as direções características do condicionamento das mineralizações para cada região da PMT abordada foram consideradas, baseando-se nas considerações preliminares obtidas por meio de compilação bibliográfica (Klein et al., 2001; Santos et al., 2001; Coutinho, 2008).

Métodos probabilísticos como pesos de evidência não se enquadram como ferramentas consistentes neste estudo de caso, visto que tal técnica requer, entre outros fatores, uma grande quantidade de pontos de treinamento, ou seja, de ocorrências de ouro, e com uma distribuição a mais uniforme possível, objetivando a minimização da incerteza. Desta forma, a lógica fuzzy e a técnica SAM foram selecionadas como métodos de modelagens para a porção oeste da PMT, já que outros critérios são levados em conta.

Os pontos críticos da aplicação da lógica fuzzy compreendem a determinação das pertinências fuzzy e a seleção crítica de quais operadores fuzzy devem ser usados, e em qual sequência de aplicação. Da mesma forma, vale ressaltar que o resultado derivado da aplicação do classificador SAM é intrínseco à escolha subjetiva do ângulo de similaridade $(\alpha)$.

0 resultado da lógica fuzzy (Fig. 8) generalizou a classificação da Suíte Intrusiva Parauari na região de ocorrência das rochas do Grupo Jacareacanga, se comparado ao resultado proporcionado pela técnica SAM (Fig. 10). Este último resultado, por sua vez, foi mais condizente com a carta metalogenética do 


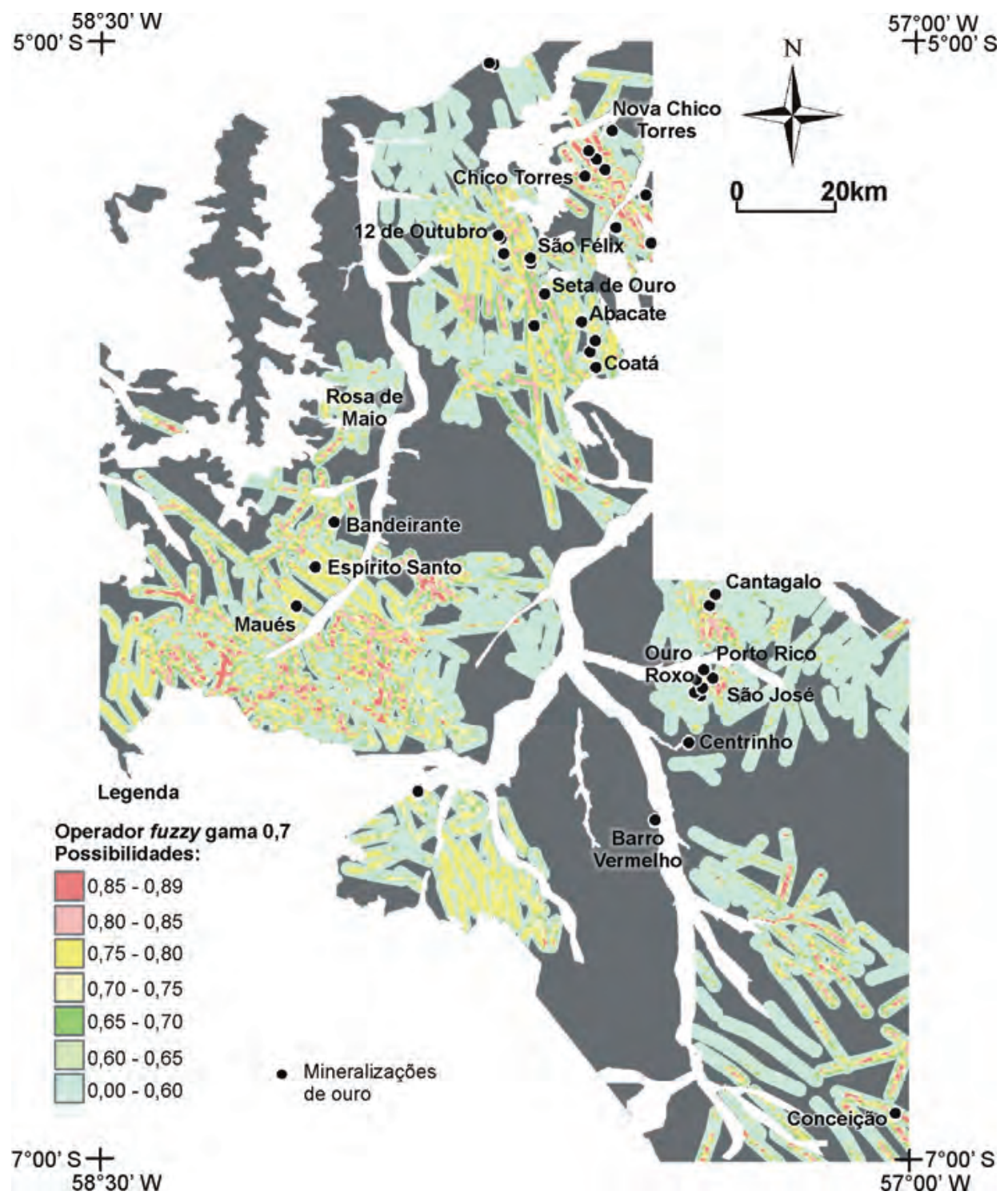

Figura 8 - Mapa previsional regional gerado pela aplicação da lógica fuzzy.

Tabela 1 - Quantificação de áreas classificadas por intervalos de possibilidades fuzzy resultantes da aplicação do operador fuzzy gama 0,7 .

\begin{tabular}{|c|c|c|}
\hline Intervalo de $\mu_{\text {fuzzy }}$ & Área classificada $\left(\mathrm{km}^{2}\right)$ & Área classificada acumulada $\left(\mathrm{km}^{2}\right)$ \\
\hline $0,80-0,89$ & 685,4 & 685,4 \\
$0,70-0,80$ & 1536,2 & 2221,6 \\
$0,60-0,70$ & 1682,9 & 3904,5 \\
$0,50-0,60$ & 733,0 & 4637,5 \\
$0,40-0,50$ & 906,5 & 5544,0 \\
$0,30-0,40$ & 1153,3 & 6697,3 \\
$0,20-0,30$ & 732,0 & 7429,2 \\
$0,10-0,20$ & 699,4 & 8128,7 \\
$0,00-0,10$ & 910,1 & (Área total classificada) $\mathbf{9 0 3 8 , 8}$ \\
\hline
\end{tabular}




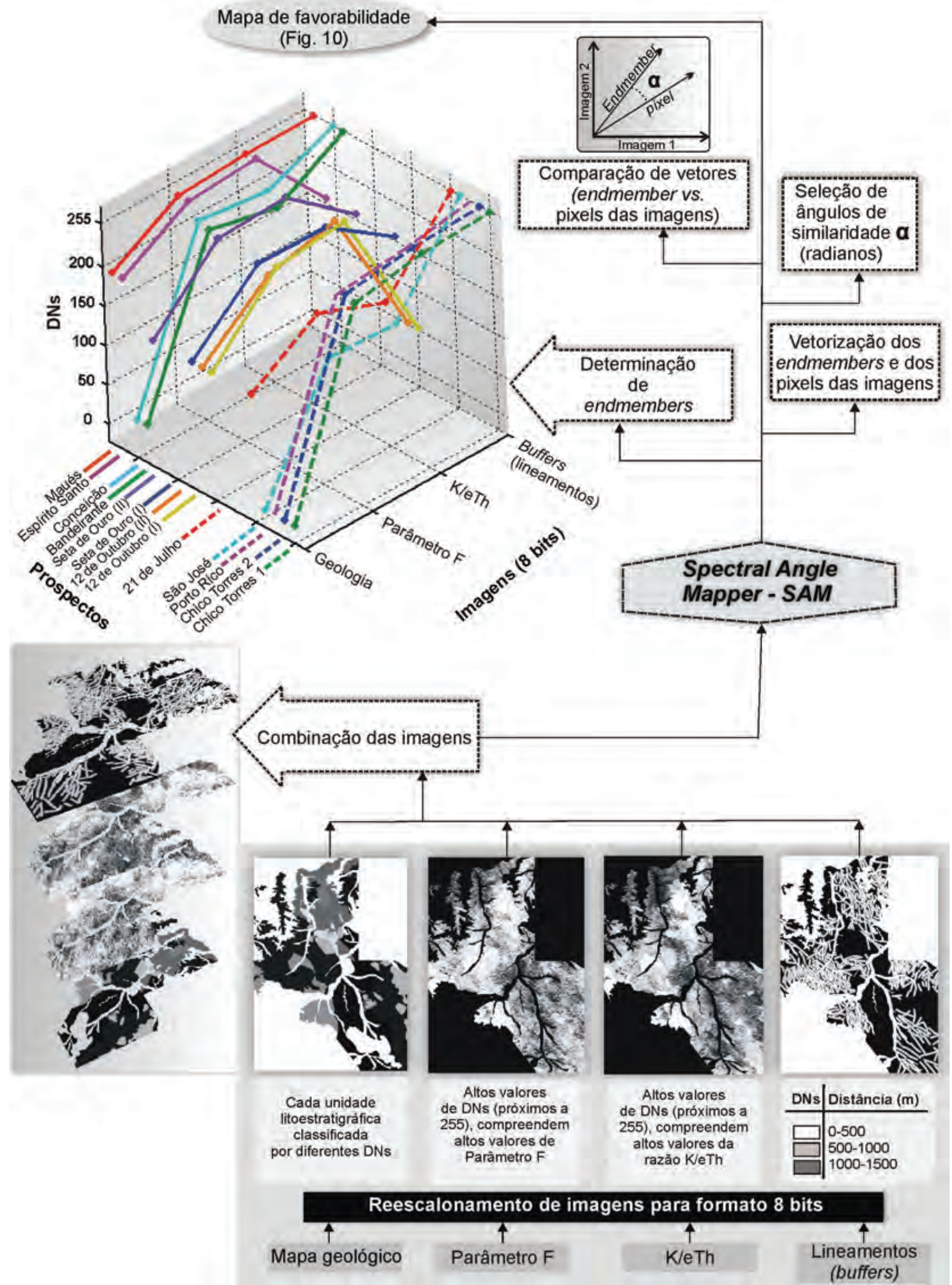

Figura 9 - Síntese das etapas envolvidas na aplicação da classificação SAM. 


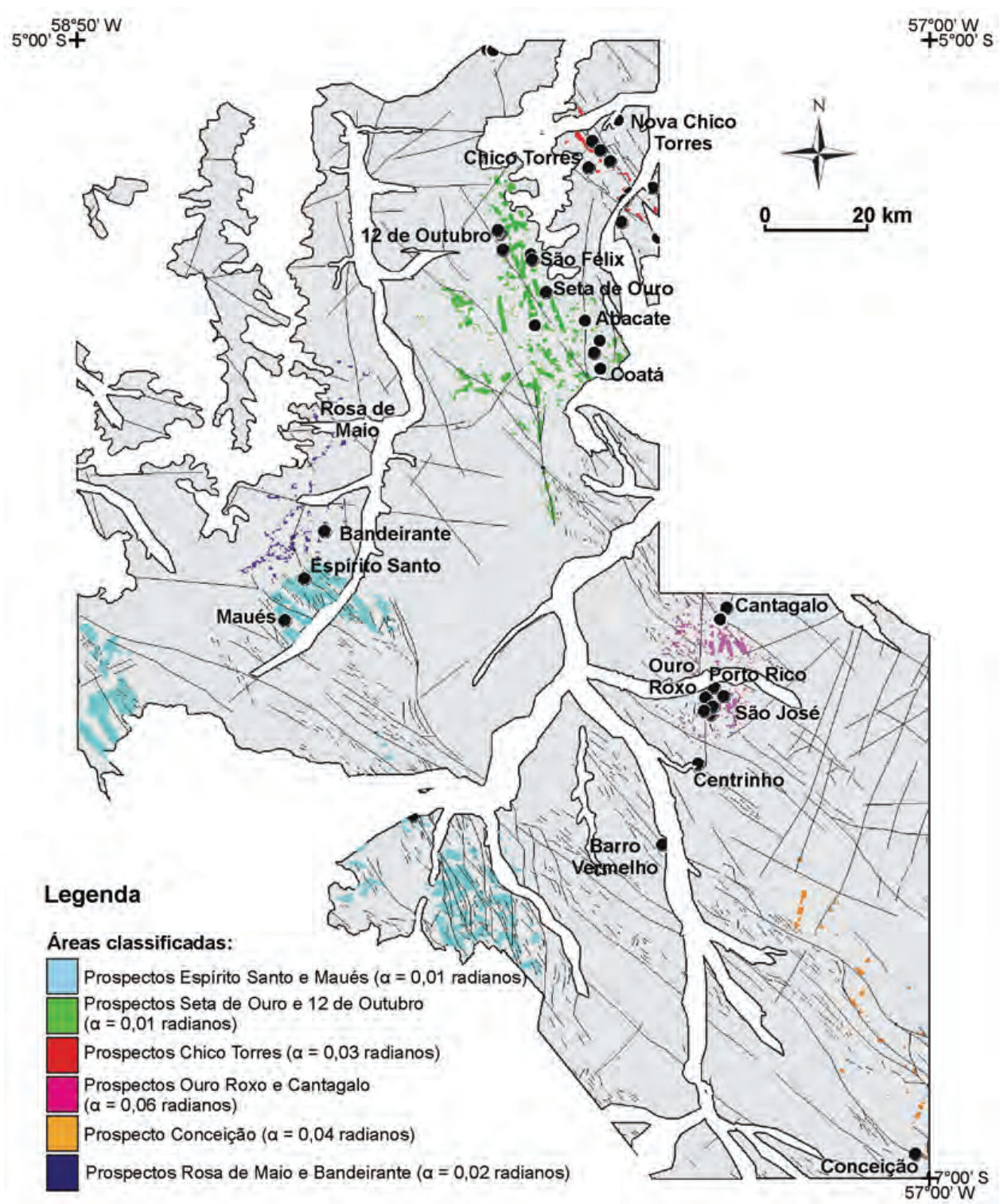

Figura 10 - Mapa previsional regional gerado a partir da aplicação da técnica SAM.

PROMIN-Tapajós (Klein et al., 2001). Os resultados mais interessantes proporcionados por ambas as técnicas estão associados com a região dos prospectos Ouro Roxo e Cantagalo (Figs. 8 e 10), os quais são coerentes com a interpretação de alvos potenciais realizada por Pedroso et al. (2001), Silva (2003) e Silva et al. (2007), e com as considerações de Klein et al. (2001) para alta prospectividade relacionada com a parte leste da zona de cisalhamento homônima, de direção N-S. Esta área em especifico merece atenção especial, reforçando as considerações já realizadas pelos autores acima, assim como a região onde se insere o prospecto Chico Torres, cujos resultados aqui apresentados também são similares (porém mais restritivos) com aqueles mostrados no mapa de potencial aurífero desenvolvido por Jacques et al. (2008).

Na região do prospecto Conceição, os resultados derivados pelo uso da lógica fuzzy e da técnica SAM destacam maior potencialidade aurífera relacionada com o trend NW-SE que, por sua vez, mostra relação com a região de contato dos granitos da Suíte Intrusiva Parauari com o Complexo Cuiú-Cuiú (Figs. 8 e 10). A técnica SAM também restringiu a área classificada em função do ângulo de similaridade selecionado.

Com relação à região dos prospectos Seta de Ouro e 12 de Outubro, houve uma generalização dos resultados gerados pela lógica fuzzy e técnica SAM (Figs. 8 e 10) principalmente 
pelo fato da consideração de dependência estrutural em direções abrangentes (NW-SE e NE-SW). Outro resultado crítico relacionase àquele produzido para a área dos prospectos Bandeirante $\mathrm{e}$ Rosa de Maio (Figs. 8 e 10). Um único ponto de treinamento (prospecto Bandeirante) obtido pelo PROMIN-Tapajós (Klein et al., 2001), em partes, explica o resultado gerado pela aplicação da técnica SAM. Para estas duas regiões, uma análise mais I0cal, preferencialmente aliada à aquisição de dados de maior detalhe que possam ser utilizados também como pontos de treinamentos, torna-se necessária para uma melhor caracterização e obtenção de resultados consistentes.

Tabela 2 - Quantificação de áreas classificadas pela aplicação da técnica SAM.

\begin{tabular}{|c|c|}
\hline $\begin{array}{c}\text { Prospectos classificados } \\
\text { pela técnica SAM }\end{array}$ & $\begin{array}{c}\text { Área classificada } \\
\left(\mathrm{km}^{2}\right)\end{array}$ \\
\hline Ouro Roxo e Cantagalo & 63,3 \\
Seta de Ouro e 12 de Outubro & 179,1 \\
Conceição & 24,9 \\
Chico Torres & 19,3 \\
Espírito Santo e Maués & 390,2 \\
Bandeirante e Rosa de Maio & 31,7 \\
Área total classificada & $\mathbf{7 0 8 , 5}$ \\
\hline
\end{tabular}

\section{CONCLUSÕES}

Os dois exemplos de mapas previsionais auríferos produzidos neste artigo são muito usados em regiões tipicamente inseridas em ambiente de baixo conhecimento geológico e exemplificam modelos exploratórios aplicados a conjunto de dados regionais existentes e de fácil disponibilidade em tais áreas.

É interessante esclarecer que, neste enfoque de análise, imagens magnetométricas, com exceção do auxílio na identificação de estruturas pertinentes aos prospectos analisados, não foram utilizadas como dados de entrada para a aplicação da lógica fuzzy e da técnica SAM, em função da grande variação de respostas para os diferentes prospectos. Por exemplo, não se sabe se os extensos diques máficos de direção NNE-SSW que afetam áreas de ocorrências auríferas possuem um papel relevante em possível reconcentração do ouro, associado ao desenvolvimento de magnetita ou desmagnetização e sua relação com eventos hidrotermais da província. Além disso, estas últimas feições devem ser observadas em dados de detalhe (Airo, 2002) e não tão regionais como os do Bloco I - Província Aurífera do Tapajós, além de ser necessário um intenso trabalho de caracterização petrofísica aliado a estudos microscópicos e mineralógicos.

Em função do pouco conhecimento e da baixa qualidade de dados disponíveis na província em questão, várias hipóteses prospectivas podem ser propostas e empregadas para a produção de mapas previsionais como tentativa de esclarecer ou revelar determinados padrões ou feições geológicas interessantes do ponto de vista metalogenético. Este contexto observado na PMT sobre conhecimento/qualidade de dados é comum em terrenos com baixo conhecimento geológico, recorrentes na região amazônica.

Inclusa nas considerações acima, está a relação de assinaturas gamaespectrométricas referentes à caracterização hidrotermal, e que ainda não foi realizada de forma eficiente para determinar padrões de respostas radiométricas típicas dos diferentes prospectos da PMT. Desta maneira, o modelo exploratório aqui usado considera altas respostas do radioelemento $\mathrm{K}$ por conta da maioria dos prospectos estudados por vários autores ser marcada por alterações hidrotermais predominantemente do tipo sericítica ou álcali-feldspática. Esta generalização do enriquecimento potássico ao modelo prospectivo caracteriza-se pelas seguintes consequências:

(a) torna crítica a aplicação de métodos de modelagens espaciais guiadas pelo conhecimento, cujo embasamento está apoiado no bom entendimento da gênese e características detalhadas das mineralizações;

(b) a generalização é fragilizada por conta da resolução dos dados gamaespectrométricos do Bloco I - Província Aurífera do Tapajós, que não permite reconhecer facilmente, em imagem, feições hidrotermais métricas (comumente observadas na província), sobrepondo-se, na maioria das vezes, o registro do sinal de background geológico.

Os resultados aqui desenvolvidos consistem em guias exploratórios regionais. Por compreender resultados muito abrangentes, recomenda-se, na medida da disponibilidade de imagens de maior detalhe acrescidas de estudos geológicos mais avançados, uma análise local e mais aprofundada por prospectos da PMT, visto que diferentes controles estruturais e alterações hidrotermais são muito variáveis em toda a extensão da província e característicos de cada prospecto. Estas variações influenciam as respostas geofísicas, por exemplo.

Da mesma forma, um banco de dados refinado de ocorrências auríferas e geoquímicas deve resultar em maior acurácia para aplicação de métodos supervisionados, ou seja, que dependam de pontos de treinamento para a previsão mineral.

\section{AGRADECIMENTOS}

Os autores agradecem aos dois revisores anônimos do manuscrito pelas sugestões, à CPRM-DIGEOF pela cessão dos dados 
aerogeofísicos, ao Sr. Carlos Alberto Ribeiro de Freitas (SIPAM/ CT0-BE) pela cessão dos dados SAR-R99B e ao CNPq pelo projeto CT-Mineral (processo $n^{\circ}$ 555063/2006-2) e pelas bolsas de produtividade em pesquisa de A.M. Silva e N.F. Botelho. T.A. Carrino agradece à CAPES pela bolsa de mestrado e ao Laboratório de Geofísica Aplicada da UnB pelo apoio técnico.

\section{REFERÊNCIAS}

AIRO ML. 2002. Aeromagnetic and aeroradiometric response to hydrothermal alteration. Surveys in Geophysics, 23(4): 273-302.

ALMEIDA FFM, HASUI Y, BRITO NEVES BB \& FUCK RA. 1981. Brazilian structural provinces: An introduction. Earth-Science Reviews, 17(1-2): $1-29$.

ALMEIDA ME, BRITO MFL, FERREIRA AL \& MONTEIRO MAS (Orgs.). 2000. Projeto Especial Província Mineral do Tapajós (PROMIN-TAPAJóS). Geologia e recursos minerais da Folha Vila Mamãe Anã (SB.21V-D), Estados do Amazonas e Pará. Escala 1:250.000. Brasília, CPRM, $67 \mathrm{p}$.

AN P, MOON WM \& RENCZ A. 1991. Application of fuzzy set theory to integrated mineral exploration. Canadian Journal of Exploration Geophysics, 27(1): 1-11.

BAHIA RBC \& QUADROS MLES (Orgs.). 2000. Projeto Especial Província Mineral do Tapajós (PROMIN-TAPAJÓS). Geologia e recursos minerais da Folha Caracol (SB.21-X-C), Estados do Amazonas e Pará. Escala 1:250.000. Manaus, CPRM, 53 p.

BIONDI JC, BARTOSZECK MK \& VANZELA GA. 2001. Análise da favorabilidade para depósitos de caulim na Bacia de Campo Alegre (SC). Revista Brasileira de Geociências, 31(1): 59-66.

BLAKELY RJ. 1996. Potential theory in gravity and magnetic applications. Cambridge, Cambridge University Press. 441 p.

BLUM ML. 1999. Processamento e interpretação de dados de geofísica aérea no Brasil Central e sua aplicação à geologia regional e à prospecção mineral. Tese (Doutorado em Geologia) - Universidade de Brasília, Brasília-DF, 229 p.

BONHAM-CARTER GF. 1994. Geographic information systems for geoscientists: modelling with GIS. Oxford, Pergamon, 398 p.

BOTELHO NF, PEREIRA KMS, MOURA MA, CLEROT LC, PINTO M \& LOPES GC. 2009. Geoquímica e inclusões fluidas das mineralizações auríferas dos prospectos Doze de Outubro e Rosa de Maio, Província Aurífera Tapajós, Amazonas. In: Simpósio Brasileiro de Metalogenia, 2: 2009, Gramado. Anais... Gramado: SBG, 2009. CD-ROM.

CARRINO TA, SOUZA FILHO CR \& LEITE EP. 2008. Cartografia do potencial de Au-Pd-Pt e EGP-Cr-Ni na região de Serra Leste (Carajás) utilizando-se a técnica ACP e classificadores hiperespectrais. Revista Brasileira de Geociências, 38(3): 501-513.
COUTINHO MGN. 2008. Evolução tectono-geológica e modelo da mineralização de ouro. In: COUTINHO MGN (Ed.). Província Mineral do Tapajós: geologia, metalogenia e mapa previsional para ouro em SIG. CPRM, Rio de Janeiro, p. 297-326.

COUTINHO MGN \& FALLICK AE. 2008. Sistema hidrotermal. In: COUTINHO MGN (Ed.). Província Mineral do Tapajós: geologia, metalogenia e mapa previsional para ouro em SIG. CPRM, Rio de Janeiro, p. 263-296.

DARDENNE MA \& SCHOBBENHAUS C. 2001. Metalogênese do Brasil. Ed. UnB, Brasília-DF, p. 78-83.

DREHER AM, VLACH SRF \& MARTINI SL. 1998. Adularia associated with epithermal gold veins in the Tapajós Mineral Province, Pará State, northern Brazil. Revista Brasileira de Geociências, 28(3): 397-404.

EFIMOV AV. 1978. Multiplikativniyi pokazatel dlja vydelenija endogennych rud aerogamma-spectrometriceskim dannym. In: Metody rudnoj geofiziki. Leningrado, Naucno-proizvodstvennoje objedinenie geofizica Ed., p. 59-68.

FERREIRA AL, ALMEIDA ME, BRITO MFL \& MONTEIRO MAS (Orgs.). 2000. Projeto Especial Província Mineral do Tapajós (PROMIN-TAPAJóS). Geologia e recursos minerais da Folha Jacareacanga (SB.21-Y-B), Estados do Amazonas e Pará. Escala 1:250.000. Manaus, CPRM, 60 p.

JACQUES PD, LEE S, COUTINHO MGN, LEE HJ \& OH HJ. 2008. Mapa previsional para ouro em Sistema de Informação Geográfica (SIG). In: COUTINHO MGN (Ed.). Província Mineral do Tapajós: geologia, metalogenia e mapa previsional para ouro em SIG. CPRM, Rio de Janeiro, p. 327-354.

JULIANI C, CORRÊA SILVA RH, MONTEIRO LVS, BETTENCOURT JS \& NUNES CMD. 2002. The Batalha Au-granite system - Tapajós Gold Province, Amazonian Craton, Brazil: hydrothermal alteration and regional implications. Precambrian Research, 119(1-4): 225-256.

JULIANI C, RYE RO, NUNES CMD, SNEE LW, CORRÊA SILVA RH, MONTEIRO LVS, BETTENCOURT JS, NEUMANN R \& ALCOVER NETO A. 2005. Paleoproterozoic high-sulfidation mineralization in the Tapajós gold province, Amazonian Craton, Brazil: geology, mineralogy, alunite argon age, and stable-isotope constraints. Chemical Geology, 215(1-4): $95-125$.

JULIANI C, FERNANDES CMD, MAPA FB, MISAS CME \& MONTEIRO LVS. 2008. A gênese do vulcano-plutonismo Uatumã e das mineralizações de Au e de metais de base associadas nas regiões do Tapajós, Iriri e Xingu (PA). In: Simpósio de Vulcanismo e Ambientes Associados, 4., 2008, Foz de Iguaçu. Anais... Foz do Iguaçu: SBG, 2008. 10 p.

KLEIN EL \& VASQUEZ ML (Orgs.). 2000. Projeto Especial Província Mineral do Tapajós (PROMIN-TAPAJÓS). Geologia e recursos minerais da Folha Vila Riozinho (SB.21-Z-A), Estados do Amazonas e Pará. Escala 1:250.000. Brasília, CPRM, 45 p. 
KLEIN EL, ALMEIDA ME, VASQUEZ ML, BAHIA RBC, SANTOS MLE \& FERREIRA AL. 2001. Geologia e recursos minerais da Província Mineral do Tapajós. Folhas Vila Mamães Anã (SB.21-V-D), Jacareacanga (SB.21-Y-B), Caracol (SB.21-X-X), Vila Riozinho (SB.21-Z-A) e Rio Novo (SB.21-Z-C). Estados do Pará e Amazonas. Escala 1:500.000. Brasília, CPRM/DIEDIG/DEPAT, $81 \mathrm{p}$.

KLEIN EL, VASQUEZ ML, ROSA-COSTA LT \& CARVALHO JMA. 2002. Geology of Paleoproterozoic gneiss- and granitoid-hosted gold mineralization in Southern Tapajós Province, Amazonian Craton, Brazil. Int. Geol. Review, 44(6): 544-558.

KLEIN EL, ROSA-COSTA LT \& CARVALHO JMA. 2004. Estudo de inclusões fluidas em veio de quartzo aurífero do prospecto Patinhas, Província Aurífera do Tapajós, Cráton Amazônico. Revista Brasileira de Geociências, 34(1): 59-66.

KRUSE FA. 1998. Advances in hiperespectral remote sensing for geologic mapping and exploration. In: $12^{\text {th }}$ JPL Airborne Geoscience Workshop, Jet Propulsion Laboratory Publication, 12.: 1998, Proceedings... JPL, p. 149-156.

KRUSE FA, LEFKOFF AB, BOARDMAN JB, HEIDEBRECHT KB, SHAPIRO AT, BARLOON PJ \& GOETZ AFH. 1993. The Spectral Image Processing Systems (SIPS) - Interactive Visualization and Analysis of Imaging spectrometer Data. Remote Sensing of Environment, 44(2-3): 145-163.

LAMARÃO CN, DALL'AGNOL R, LAFON J-M \& LIMA EF. 2002. Geology, geochemistry, and $\mathrm{Pb}-\mathrm{Pb}$ zircon geochronology of the paleoproterozoic magmatism of Vila Riozinho, Tapajós Gold Province, Amazonian Craton, Brazil. Precambrian Research, 119(1-4): 189-223.

LAMARÃO CN, DALL'AGNOL R \& PIMENTEL MM. 2005. Nd isotopic composition of Paleoproterozoic volcanic and granitoid rocks of Vila Riozinho: implications for the crustal evolution of the Tapajós Gold Province, Amazon Craton. Journal of South American Earth Sciences, 18(3-4): 277-292.

LASA ENGENHARIA E PROSPECÇÕES S.A. 1998. Projeto aerogeofísico Província Aurífera do Tapajós (Bloco le ll): relatório final do levantamento e processamento dos dados magnetométricos e gamaespectrométricos. Volume 1. Texto técnico.

METELO MJ, COUTINHO MGN \& AZEVEDO MLV. 2008. Aerogeofísica. In: COUTINHO MGN (Ed.). Província Mineral do Tapajós: geologia, metalogenia e mapa previsional para ouro em SIG. CPRM, Rio de Janeiro, p. 77-94.

MIETHKE C, SOUZA FILHO CR \& SILVA AM. 2007. Assinatura geofísica e modelos prospectivos 'knowledge-driven' de mineralizações de Au no lineamento Congonhas, sul do Cráton São Francisco, MG. Revista Brasileira de Geociências, 37(3): 490-503.

MINTY BRS. 1991. Simple micro-levelling for aeromagnetic data. Exploration Geophysics, 22(4): 591-592.
NABIGHIAN NM. 1972. The analytic signal of two-dimensional magnetic bodies with polygonal cross section: its properties and use for automated anomaly interpretation. Geophysics, 37(3): 507-517.

NABIGHIAN NM. 1974. Additional comments on the analytic signal of two-dimensional magnetic bodies with polygonal cross section. Geophysics, 39(1): 85-92.

PEDROSO EC, RIVARD B, CRÓSTA AP, SOUZA FILHO CR \& MIRANDA FP. 2001. Reconnaissance geologic mapping in the Tapajós Mineral Province, Brazilian Amazon, using spaceborne SAR imagery and airborne geophysics. Canadian Journal of Remote Sensing, 27(6): 669-678.

PEREGOVICH B, MATHIS A \& GOMES RSS. 2008. Transition from small-scale artisanal gold mining to large-scale corporate mining in the Tapajós Mineral Province, Brazil. In: XLIV Congr. Bras. Geol., 44: 2008, Curitiba. Anais... Curitiba: SBG, 2008, p. 188.

PEREIRA KMS, MOURA MA \& BOTELHO NF. 2008. Caracterização do fluido mineralizador em garimpos de ouro da Província Aurífera Tapajós, Amazonas. In: XLIV Congr. Bras. Geol., 44: 2008, Curitiba. Anais... Curitiba: SBG, 2008, p. 867.

PINTO M, BOTELHO NF, CLEROT LC, CUNHA LM, CARRINO TA \& CORRÊA PM. 2009. Geologia e geoquímica dos prospectos auríferos Doze de Outubro, Rosa de Maio, Bandeirante e Maués, Província Mineral do Tapajós, Amazonas. In: Simpósio de Geologia da Amazônia, 11: 2009, Manaus. Anais... Manaus: SBG, 2009. CD-ROM.

QUADROS TFP, KOPPE JC, STRIEDER AJ \& COSTA JFCL. 2003. Gamma-ray data processing and integration for lode-Au deposits exploration. Natural Resources Research, 12(1): 57-65.

RODRIGUES JL, BRAGA JBP, OLIVEIRA RAF \& DANIN T. 2008. Tapajós Mineral: um novo ciclo de oportunidades e domínios. In: XLIV Congr. Bras. Geol., 44: 2008, Curitiba. Anais... Curitiba: SBG, 2008, p. 187.

ROEST WR, VERHOEF J \& PILKINGTON M. 1992. Magnetic interpretation using 3-D analytic signal. Geophysics, 57(1): 116-125.

ROWAN LC \& MARS JC. 2003. Lithologic mapping in the Mountain Pass, California area using Advanced Spaceborne Thermal Emission and Reflection Radiometer (ASTER) data. Remote Sensing of Environment, 84(3): 350-366.

SANTOS RA \& COUTINHO MGN. 2008. Geologia estrutural. In: COUTINHO MGN (Ed.). Província Mineral do Tapajós: geologia, metalogenia e mapa previsional para ouro em SIG. CPRM, Rio de Janeiro, p. 95-134.

SANTOS JOS, HARTMANN LA, GAUDETTE HE, GROVES DI, MCNAUGHTON NJ \& FLETCHER IR. 2000. A new understanding of the provinces of the Amazon Craton based on integration of field mapping and U-Pb and Sm-Nd geochronology. Gondwana Research, 3(4): 453-488.

SANTOS JOS, GROVES DI, HARTMANN LA, MOURA MA \& MCNAUGHTON NJ. 2001. Gold deposits of the Tapajós and Alta Floresta domains, Tapajós-Parima orogenic belt, Amazon Craton, Brazil. Mineralium Deposita, 36(3-4): 278-299. 
SANTOS JOS, HARTMANN LA, McNAUGHTON NJ \& FLETCHER IR. 2002. Timing of mafic magmatism in the Tapajós Province (Brazil) and implications for the evolution of the Amazon Craton: evidence from baddeleyite and zircon U-Pb SHRIMP geochronology. Journal of South American Earth Sciences, 15: 409-429.

SANTOS JOS, VAN BREEMEN OB, GROVES DI, HARTMANN LA, ALMEIDA ME, McNAUGHTON NJ \& FLETCHER IR. 2004. Timing and evolution of multiple paleoproterozoic magmatic arcs in the Tapajós Domain, Amazon Craton: constraints from SHRIMP and TIMS zircon, baddeleyite and titanite U-Pb geochronology. Precambrian Research, 131(1-2): 73-109.

SANTOS JOS, HARTMANN LA, RIKER SR, SOUZA MM, ALMEIDA ME \& McNAUGHTON NJ. 2006. A compartimentação do Cráton Amazonas em províncias: avanços ocorridos no período 2000-2006. In: Simpósio de Geologia da Amazônia, 9., 2006, Belém. Anais... Belém: SBG, 2006, resumos expandidos. CD-ROM.

SILVA AAC. 2003. Processamento, interpretação e integração de dados geológicos e geofísicos da Província Mineral do Tapajós. Dissertação (Mestrado em Geologia) - Universidade de Brasília, Brasília-DF, 137 p.

SILVA AAC, SILVA AM \& FUCK RA. 2007. Interpretação de dados aerogeofísicos da Província Mineral do Tapajós aplicada à geologia regional e prospecção de ouro. In: ROSA-COSTA LT, KLEIN EL, VIGLIO EP (Orgs.). Contribuições à Geologia da Amazônia. SBG - Núcleo Norte, Belém, vol. 5, p. 63-74.
SOARES MS, KOPPE JC, COSTA JFCL \& ROLIM SB. 2004. Interpretação das anomalias de potássio hidrotermal e parâmetro $F$ da região do Complexo Bossoroca, São Sepé, RS. Revista Escola de Minas, 57(1): 39-44.

TASSINARI CCG \& MACAMBIRA M. 1999. Geochronological Provinces of the Amazonian Craton. Episodes, 22(3): 174-182.

TASSINARI CCG \& MACAMBIRA M. 2004. A evolução tectônica do Cráton Amazônico. In: MANTESSO-NETO V, BARTORELLI A, CARNEIRO CDR, BRITO NEVES BB (Orgs.). Geologia do Continente Sul Americano: Evolução da obra de Fernando Flávio Marques de Almeida. São Paulo, BECA, p. 471-486.

VASQUEZ ML \& KLEIN EL (Orgs.). 2000. Projeto Especial Província Mineral do Tapajós (PROMIN-TAPAJÓS). Geologia e recursos minerais da Folha Rio Novo (SB.21-Z-C), Estados do Amazonas e Pará. Escala 1:250.000. Brasília, CPRM, 45 p.

VASQUEZ ML, RICCI PSF \& KLEIN EL. 2002. Granitóides pós-colisionais da porção leste da Província Tapajós. In: KLEIN EL, VASQUEZ ML \& ROSA-COSTA LT (Eds.). Contribuições à geologia da Amazônia. SBGNúcleo Norte, Belém, 3: 67-83.

VELOSO ASR, SANTOS MD, SANTOS WP \& SNEE LW. 2008. Relação entre a mineralização aurífera do depósito Ouro Roxo e a zona de cisalhamento Ouro Roxo-Cantagalo, Província Tapajós, Pará. In: XLIV Congr. Bras. Geol., 44: 2008, Curitiba. Anais... Curitiba: SBG, 2008, p. 169.

\section{NOTAS SOBRE OS AUTORES}

Thais Andressa Carrino. Geóloga (UNICAMP, 2007) e Mestre em Geologia (UnB, 2010). Suas áreas de interesse são processamento e interpretação de imagens de sensoriamento e aerogeofísicas, e modelagem de dados com foco em exploração de recursos naturais.

Adalene Moreira Silva. Engenheira Geóloga (1989) graduada pela Universidade Federal de Ouro Preto, Mestre (1992) e Doutora em Geologia (1999) pela Universidade de Brasília. Pesquisadora do Serviço Geológico Americano (1997-1999), Professora Visitante da Universidade de Brasília (2000-2002), Pesquisadora (05/200204/2003) e Professora do Instituto de Geociências da UNICAMP (04/2003-10/2005). Professora Colaboradora Voluntária do Instituto de Geociências da UNICAMP (11/2005-11/2009). É Professora do Instituto de Geociências da UnB (Quadro Permanente) e Secretária de Relações Acadêmicas da Sociedade Brasileira de Geofísica. Atua na área de Geociências, com ênfase em Geofísica Aplicada, com foco em novas técnicas de processamento, interpretação e integração de dados aplicados a exploração mineral, hidrogeologia e ambiente. De 1997 a 2012 recebeu auxílios à pesquisa do CNPq, CAPES, FAPESP, USGS (EUA), WISC - AAAS Program - NSF (Women's International Science Collaboration - American Association for the Advancement of Science - National Science Foundation), Programa Petrobras Ambiental, Instituto Tecnológico Vale.

Nilson Francisquini Botelho. Possui graduação em Geologia pela Universidade de Brasília (1981), mestrado em Geologia pela Universidade de Brasília (1984) e doutorado em Geologia - Université de Paris VI (Pierre et Marie Curie) (1992). Atualmente é Professor Titular da Universidade de Brasília. Tem experiência na área de Geociências, com ênfase em Mineralogia, Petrologia e Metalogenia, atuando principalmente nos seguintes temas: granito, alteração hidrotermal, ouro, cobre, estanho e outros metais raros. Desenvolve projetos de pesquisa nos estados de Goiás, Tocantins e Amazonas e nas províncias minerais de Carajás e do Tapajós.

Alexandre Augusto Cardoso da Silva. Geólogo (2000) e Mestre (2003) pela Universidade de Brasília com ênfase, neste último, em geologia regional e prospecção de ouro utilizando dados magnéticos e gamaespectrométricos. Trabalha como geofísico na Petróleo Brasileiro S.A. desde 2002, principalmente na área de inversão sísmica e sísmica 4D. 